\title{
基于有机小分子的焦磷酸根荧光探针研究进展
}

\author{
徐勤超 金 灿朱雪慧邢国文* \\ (北京师范大学化学学院 北京 100875)
}

\begin{abstract}
摘要 焦磷酸根(PPi)作为一种重要的生物功能阴离子在生命科学、环境科学、药物领域和化学过程等方面起着非常重 要的作用. 鉴于荧光分析具有操作简便、灵敏度高等突出优点，设计合成高效的 PPi 荧光探针成为近年来超分子化学研 究的热点之一. 综述了近年来 PPi 苂光识别与传感的多种设计策略与原理，主要包括基于荧光增强或淬灭型识别，激基 缔合物识别，荧光指示剂置换，静电或氢键作用识别等. DPA-金属离子络合物，尤其是 DPA- $\mathrm{Zn}^{2+}$ 络合物，作为识别基 团对 PPi 有着显著的亲和性和选择性识别能力. DPA- $Z n^{2+}$ 络合物与多种荧光团或者荧光指示剂组合而形成的化学传感 体系已经被广泛应用于 PPi 苂光识别与传感.
\end{abstract}

关键词＼cjkstart荧光探针；焦磷酸根；金属离子络合物；激基缔合物；指示剂置换

\section{Recent Progress in Fluorescent Probes for Pyrophosphate Based on Small Organic Molecules}

\author{
$\mathrm{Xu}$, Qinchao Jin, Can Zhu, Xuehui Xing, Guowen* \\ (College of Chemistry, Beijing Normal University, Beijing 100875)
}

\begin{abstract}
Pyrophosphate (PPi), a kind of important biological functional anion, plays crucial roles in life science, environmental science, medicine and chemical process. It has attracted extensive interests in supramolecular chemistry to design efficient fluorescent PPi sensors due to the simplicity and high sensitivity of fluorometric analysis. In this review, several kinds of strategies and theories of PPi fluorescent recognition and sensing are summarized, including off-on/on-off fluorescent response, excimer formation, hydrogen-bonding or electrostatic interactions and fluorescent indicator displacement assay. DPA-metal ion complexes, especially DPA- $\mathrm{Zn}^{2+}$ complex, have remarkable binding affinity and high selectivity for PPi. The chemosensing ensembles, consisting of DPA- $\mathrm{Zn}^{2+}$ complex and various fluorophores or fluorescent indicators, have been widely applied to the PPi fluorescent recognition and sensing.
\end{abstract}

Keywords fluorescent sensor; pyrophosphate; metal ion complex; excimer; indicator displacement

阴离子广泛存在于生物体内和周围环境中, 在生命 科学、环境科学、药物领域和化学过程等方面起着非常 重要的作用. 焦磷酸根(pyrophosphate, PPi) 是一种具有 重要生物功能的阴离子, 参与生物体中诸多能量转化和 新陈代谢过程. PPi 是活细胞中三磷酸腺苷水解的产物, 其稳定的代谢过程保证了生物体功能的正常运转. 在 DNA 聚合酶催化下, PPi 与 DNA 的复制、遗传信息的处 理等过程密切相关 ${ }^{[1]}$. 以此为基础, PPi 的检测已经发展 成为一种实时 DNA 测序的方法 ${ }^{[2]}$. 另外, 由于端粒酶在 合成碱基重复序列时伴随有 PPi 的释放, 与 PPi 相关的 生物发光分析也应用于肿瘤诊断 ${ }^{[3]}$. 鉴于上述焦磷酸根
的重要研究价值, 其选择性检测已经成为近年来超分子 化学领域的研究热点之一 ${ }^{[4]}$.

荧光是一种广泛应用并且发展迅速的传感检测手 段, 以其灵敏度高, 可实时原位检测(苂光成像技术), 可视亚纳米空间分辨能力和亚毫秒时间分辨能力以及 光纤远程检测等突出优点而备受关注. 菼光探针是一类 能将分子识别事件通过荧光信号有效表达的分子或复 合物. 一般包括两部分：受体(识别基团)和信号单元(荧 光团或发色团). 前者用来识别特定的被分析物，而后 者则承担将识别过程转化为荧光响应信号的功能. 这两 个部分可通过共价键或者非共价键连接. 从荧光信号响

* E-mail: gwxing@bnu.edu.cn

Received November 26, 2013; revised December 12, 2013; published online December 23, 2013.

Project supported by the National Natural Science Foundation of China (No. 21272027), the Beijing Natural Science Foundation (No. 2122031), and the Beijing Municipal Commission of Education.

国家自然科学基金(No. 21272027)、北京市自然科学基金(No. 2122031)和北京市教育委员会共建项目专项资助项目. 
应类型来看，荧光探针大体可以分为增强型(Off-on)荧 光探针、淬灭型(On-off)荧光探针和比率型荧光探针. 增 强型荧光探针在一定程度上提高了信噪比, 较淬灭型荧 光探针在灵敏度方面有明显提高. 而比率荧光信号则优 于荧光强度响应信号, 不仅提高了灵敏度, 还易引入自 动校准功能, 从而实现被分析物的定量检测.

理想的苂光探针具有以下基本特征：首先，受体与 待分析物具有很好的选择性识别作用; 其次, 在高选择 性识别的基础上，通过合适的荧光团呈现良好的荧光信 号变化, 并且检测过程不易受 $\mathrm{pH}$ 值和温度等环境因素 的干扰. 一般而言, 识别基团的选择性优劣对荧光探针 的性能有决定性影响.

1994 年, Czarnik 研究组 ${ }^{[5]}$ 首次报道了基于静电相互 作用以葱为荧光团, 多胺为识别基团的水溶性 PPi 荧光 探针. 在此之后的十几年中, 有关 PPi 的荧光检测研究 取得了较大的进展. 总的来说, 有关 PPi 检测的荧光探 针根据识别方式的不同主要分为以下几类: 苂光增强或 淬灭型识别、激基缔合物识别、基于静电或氢键作用识 别等. 值得注意的是, 近年来基于荧光指示剂置换法设 计策略的 PPi 荧光探针也发展迅速, 已经成为 PPi 荧光 识别与传感的重要研究内容. 下面对近年来 PPi 荧光检 测的研究进展进行总结和评述.

一般而言, 由于金属离子不仅可以与含氮多齿配体 配位, 同时也可以与 PPi 结合形成复合物, 因此最为常 见的 PPi 识别基团是 DPA-金属离子络合物[DPA: $N, N^{\prime}-$ 二(2-吡啶甲基)胺]. 迄今为止, 已经发现多种 $\mathrm{DPA}-\mathrm{M}^{2+}$ (M: $\mathrm{Zn}^{2+}, \mathrm{Cd}^{2+}, \mathrm{Cu}^{2+}$ 等)络合物对焦磷酸根具有较强的 亲和性, 发展出一系列以 $\mathrm{DPA}-\mathrm{M}^{2+}$ 为识别基团的 $\mathrm{PPi}$ 苂 光探针.

\section{1 基于荧光增强或淬灭型识别}

2003 年, Hong 研究组 ${ }^{[6]}$ 首次报道了含有双 DPA- $\mathrm{Zn}^{2+}$ 络合单元，以偶氮酚为发色团的 PPi 比色探针 1. 该探针 对 PPi 具有较高的亲和性 $\left(K_{\mathrm{a}}=6.6 \times 10^{8} \mathrm{~L} \cdot \mathrm{mol}^{-1}\right)$, 远高 于其他重要的生物阴离子, 如柠檬酸根, $\mathrm{CH}_{3} \mathrm{COO}^{-}$, $\mathrm{HSO}_{4}^{-}, \mathrm{H}_{2} \mathrm{PO}_{4}^{-}, \mathrm{F}^{-}$等. 在 $\mathrm{PPi}$ 存在下, 探针水溶液颜 色由黄色变为红色, 而其他阴离子则不能引起溶液颜色 的变化. 探针 1 与 PPi 的 1: 1 的络合模式由 $\mathrm{X}$ 射线单 晶衍射实验证实. 单晶结构显示 $\mathrm{PPi}$ 中四个 $\mathrm{P}-\mathrm{O}$ 单键 上的氧原子同时与两个锌离子配位，从而将两个金属离 子桥连起来, 所形成的两个六配位锌离子配合物形似 “三明治” 结构, PPi 位于两个 DPA- $\mathrm{Zn}^{2+}$ 络合单元之间. 由于 $\mathrm{P}-\mathrm{O}$ 键与锌离子配位后削弱了锌离子与发色团上 酚氧原子之间的相互作用, 导致探针的最大吸收波长红 移了 $46 \mathrm{~nm}$. 该探针的设计策略为此后基于 DPA- $\mathrm{M}^{2+}$ 受
体的 PPi 苂光探针的发展奠定了良好的基础.

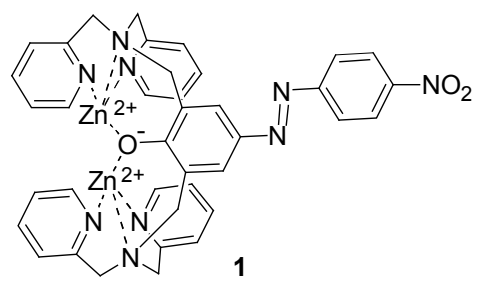

荧光素作为一种重要的荧光标记染料, 具有较大的 摩尔消光系数、较高的荧光量子产率以及良好的光稳定 性. 另外, 使用可见光激发使得荧光素应用于细胞标记 成为可能. 因此, 苂光素作为一种性质优良的信号报告 基团见于各种荧光探针的设计中. Yoon 等 ${ }^{[7]}$ 报道了以荧 光素为菼光团, DPA- $\mathrm{Zn}^{2+}$ 络合单元为识别基团的 PPi 荧 光探针 2. 该探针在水溶液中对 PPi 具有较高的选择性, 其他常见阴离子如 $\mathrm{HSO}_{4}^{-}, \mathrm{CH}_{3} \mathrm{COO}^{-}, \mathrm{I}^{-}, \mathrm{Br}^{-}, \mathrm{Cl}^{-}, \mathrm{F}^{-}$, $\mathrm{H}_{2} \mathrm{PO}_{4}^{-}$对其荧光性质几乎没有影响, 可以作为一个较 好的比率型荧光探针. 以 $517 \mathrm{~nm}$ 为激发波长, 随着 $\mathrm{PPi}$ 的加入，探针 2 最大荧光发射峰由 $523 \mathrm{~nm}$ 红移至 534 $\mathrm{nm}$ ，呈现出明显的螯合荧光增强效应 $(150 \%)$. 该探针的 显著优势在于其较大的荧光激发波长和发射波长使其 具有较好的生物应用潜力. 此外, 探针 $\mathbf{2}$ 的比率型荧光 响应也使其易于实现 PPi 的定量检测.

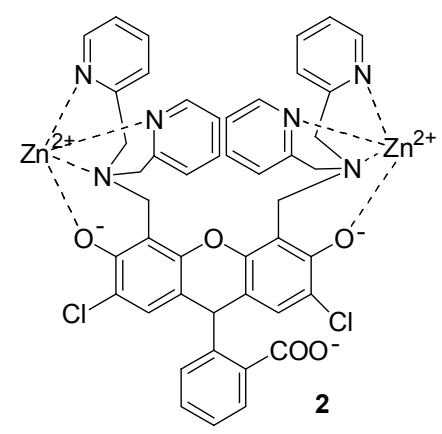

2007 年, Yoon 等 ${ }^{[8]}$ 报道了一个以吅啶为荧光团, DPA $-Z^{2+}$ 为受体的 PPi 荧光探针 3 . 在 $100 \%$ 的水溶液 中, 该探针对 PPi 呈现出较强的螯合荧光淬灭效应 (CHEQ), 并伴随有 $20 \mathrm{~nm}$ 的红移; 而对 $\mathrm{Pi}\left(\mathrm{HPO}_{4}^{2-}\right)$ 却表 现出有效的螯合荧光增强效应(CHEF); 加入一些常见 的阴离子 $\left(\mathrm{HSO}_{4}^{-}, \mathrm{CH}_{3} \mathrm{COO}^{-}, \mathrm{I}^{-}, \mathrm{Br}^{-}, \mathrm{Cl}^{-}, \mathrm{F}^{-}\right)$均不会引 起探针 3 苂光信号的变化. 与 $\mathrm{PPi}$ 相关的 $\mathrm{CHEQ}$ 效应推 测由 PET(光电子诱导转移)荧光机制导致，当 $\mathrm{PPi}$ 与 $\mathrm{Zn}^{2+}$ 结合时, 减弱了 $\mathrm{Zn}^{2+}$ 与探针分子中苠胺氮原子的配 位作用, 从而诱导了从芐胺氮原子到呋啶荧光团的 PET 过程，导致荧光淬灭. 而对 $\mathrm{Pi}$ 的 $\mathrm{CHEF}$ 效应则是叫啶上 的氮原子与 $\mathrm{Pi}$ 之间形成的氢键所致. 探针 3 与 $\mathrm{PPi}$ 和 $\mathrm{Pi}$ 的结合常数分别为 $4.85 \times 10^{7}$ 和 $9.36 \times 10^{4} \mathrm{~L} \cdot \mathrm{mol}^{-1}$, 对 
PPi 的检测限可达纳摩尔浓度级.

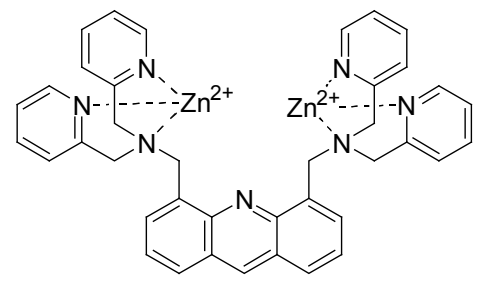

3

Pang 及其合作者 ${ }^{[9]}$ 设计合成了以苯并噁唑为苂光 团、DPA- $\mathrm{Zn}^{2+}$ 络合单元为识别基团的 PPi 荧光探针 4. 该 探针通过激发态分子内质子转移(ESIPT) 荧光机制实现 了对 PPi 的高效检测. 在 PPi 存在下, 通过其桥连两个 $\mathrm{DPA}-\mathrm{Zn}^{2+}$ 单元, 引发了激发态质子向酚氧原子的转移, 在苯并噁唑荧光团部分形成分子内氢键 4-PPi, 荧光辐 射由蓝色变为绿色, 最大发射波长从之前的 $420 \mathrm{~nm}$ 红 移至 $518 \mathrm{~nm}$, 红移了约 $100 \mathrm{~nm}$. 相比之下, 其他阴离子 如 ATP(三磷酸腺苷)等不能诱导 ESIPT 红移. 因此, 以 化合物 4 为荧光探针实现了 PPi 的高选择性识别.

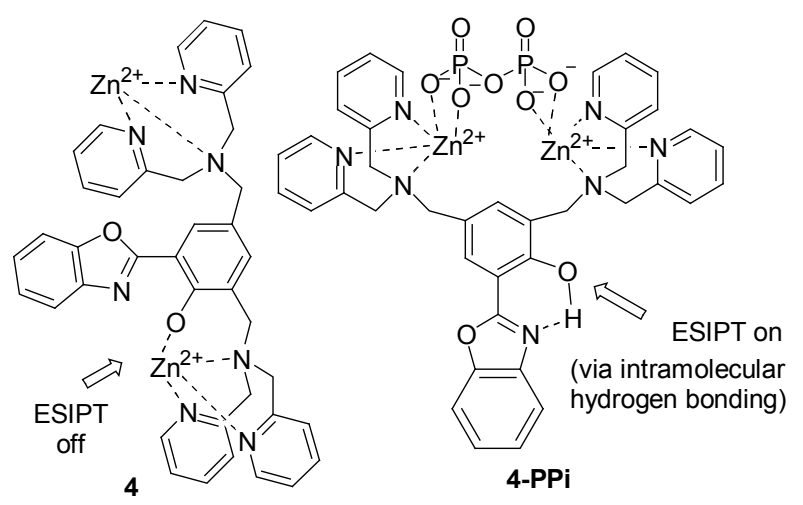

香豆素因其高的量子产率、较大的 Stokes 位移、结 构简单、易于引入推拉电子基团等优点, 被广泛用于各 类荧光探针的设计. 2009 年, Yoon 等 ${ }^{[10]}$ 以 7-羟基香豆素 为荧光团, 分别在其 8 位和 4 位引入 $\mathrm{DPA}-\mathrm{Cu}^{2+}$ 识别基 团合成了 PPi 探针 $5 \mathbf{a}$ 和 $\mathbf{5 b}$. 单晶结构证实在 $\mathbf{5 a}$ 分子中, 硝酸根离子桥连两个 $\mathrm{DPA}-\mathrm{Cu}^{2+}$ 络合单元, 酚氧原子和 水分子参与配合物的形成; 而 $\mathbf{5 b}$ 中 DPA 螯合铜离子仅 形成单核的络合物. 在 $5 \mathbf{a}$ 和 $\mathbf{5 b}$ 的水溶液中分别加入 $\mathrm{PPi}, \mathrm{ATP}, \mathrm{ADP}$ (二磷酸腺苷), AMP(一磷酸腺苷), $\mathrm{Pi}, \mathrm{F}^{-}$, $\mathrm{Br}^{-}, \mathrm{I}^{-}, \mathrm{Cl}^{-}, \mathrm{CH}_{3} \mathrm{CO}_{2}^{-}, \mathrm{HSO}_{4}^{-}$, 只有 $\mathrm{PPi}$ 可引起较大 的苂光增强效应, 表明该类探针对 PPi 有较好的选择性. 与 $5 \mathbf{a}$ 相比, $\mathbf{5 b}$ 在加入 PPi 后荧光增强的倍数相对较高 (20 倍). 另外, 如果将 DPA-Cu ${ }^{2+}$ 络合单元换成 DPA$\mathrm{Zn}^{2+}$ 络合单元, 则探针分子对阴离子均没有响应. 由此 可见, DPA- $\mathrm{M}^{2+}$ 络合中心金属离子的种类对探针的荧光
性质有很大的影响.
$5 a$

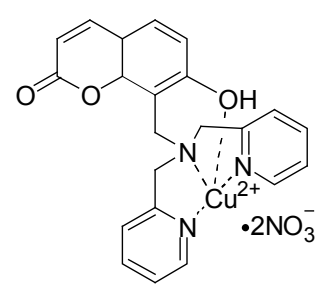<smiles>O=c1cc(CN2Cc3ccccc3C2)c([N+](=O)[O-])cn1Cc1ccccn1</smiles>

5b
随后, 2011 年 Das 研究组 ${ }^{[11]}$ 报道了两个基于 $\mathrm{DPA}-\mathrm{Zn}^{2+}$ 和 DPA-Cd ${ }^{2+}$ 受体, 硝基香豆素为荧光团的 PPi 苂光探针 6a 和 $\mathbf{6 b}$. 这两个探针均可以在纯水中对 PPi 有较高的选择性, 不同的是探针 $\mathbf{6 a}$ 对 PPi 呈现出螯 合苂光增强效应，而 $6 \mathbf{b}$ 对 PPi 表现出螯合苂光淬灭效 应. 基于碱性磷酸酶可以催化焦磷酸根的水解，该类探 针被成功地应用于实时监测碱性磷酸酶的活性.

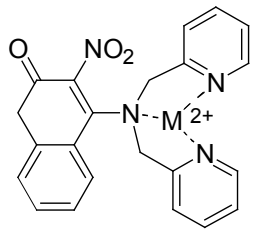

6a $\mathrm{M}=\mathrm{Zn}$

6b $M=C d$

2011 年 $H o n g$ 等 ${ }^{[12]}$ 将两个香豆素荧光团和两个 DPA- $\mathrm{Zn}^{2+}$ 单元通过苯环连接起来形成一个水溶性较好 的 PPi 苂光探针 7. 该探针的苂光在水溶液中可以被 PPi 和 ATP 有效淬灭, 但 PPi 的淬灭能力是 ATP 的 2 倍, 其 他阴离子如 ADP, AMP, Pi 等均不能诱导苂光发生明显 变化. 该探针对对 PPi 检测限较低 $\left(49 \mathrm{nmol} \cdot \mathrm{L}^{-1}\right)$.

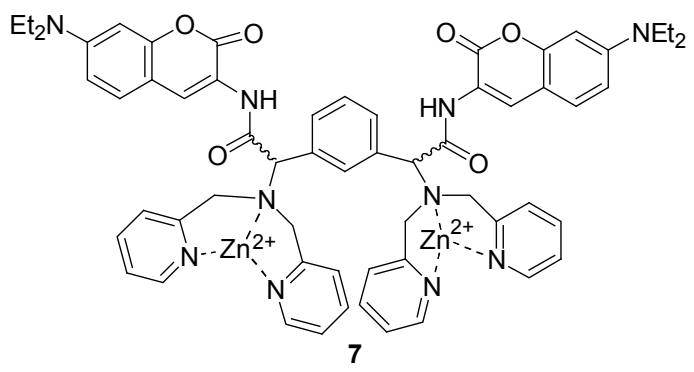

萗酰亚胺以荟环为苂光母体, 光谱呈现菜的光谱特 征, 具有光化学性质稳定、激发及发射波长较长、Stokes 位移大以及对 $\mathrm{pH}$ 不敏感等优点, 已被广泛用于设计各 种金属离子苂光传感器. Kim 等 ${ }^{[13]}$ 发展了基于 1,8 -荎酰 亚胺荧光团的苂光探针 8. 该探针属于 On-off 型苂光探 针, PPi 和 ATP 的加入都能导致不同程度的荧光淬灭. 但是, PPi 可诱导其最大发射波长发生较大的蓝移(23 $\mathrm{nm})$, 而 ATP 对其最大发射波长没有影响. 因此, 基于 以上实验结果可以实现探针 $\mathbf{8}$ 对 PPi 的选择性检测. 相 
比大多数此类 $\mathrm{PPi}$ 探针中两个锌离子均参与络合 $\mathrm{PPi}$, 在该探针络合模型中推测 $\mathrm{PPi}$ 仅与其中一个锌离子络 合. 探针 8 可用于 $\mathrm{C} 2 \mathrm{C} 12$ 细胞对外源性 PPi 浓度响应的 荧光成像.

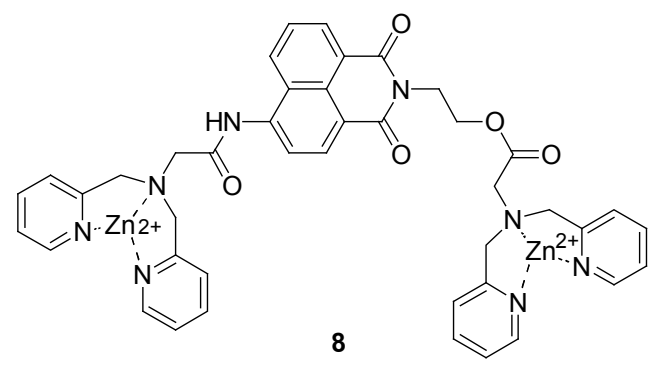

除 DPA 外, BPEA [N,N-二(2-吡啶甲基)乙二胺 $]^{[14]}$ 也是常用的锌离子螯合配体之一. Guo 等 ${ }^{[15]}$ 报道了使用 苯并噁二唑为发色团, 分别以 BPEA- $Z^{2+}$ 和 DPA- $Z^{2+}$ 为识别基团的苂光传感器 $9 a$ 和 $9 b$. 该类探针在水溶液 中具有较好的溶解性, 不足之处是对 $\mathrm{pH}$ 值变化较为敏 感. 探针 $9 \mathrm{a}$ 在 $\mathrm{pH} 7.2$ 的水溶液中本身荧光不明显, 加入 PPi 后荧光强度明显增加, 其他常见阴离子均对其荧光 性质没有影响, 表现出对 PPi 具有较好的选择性和较高 的灵敏度. 探针 9b 在相同条件下对 PPi 没有响应. 由此 可见, 识别基团的微小差异对传感器的性能起着举足轻 重的作用.
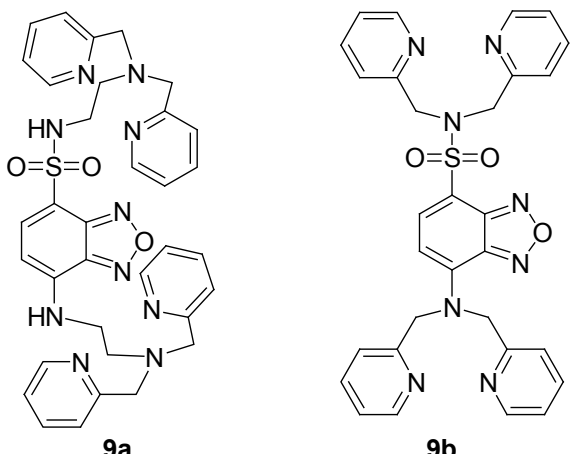

9b

2012 年 Feng 等 ${ }^{[16]}$ 报道了以硝基取代的苯并噁二唑 $(\mathrm{NBD})^{[17]}$ 为荧光团, 双 DPA- $\mathrm{Zn}^{2+}$ 络合单元为识别基团 的 PPi 比色探针 10. 在其水溶液中加入 PPi 后溶液颜色 由红色变成紫色, 除了过量的 ATP 使其颜色有轻微变 化外, 其他过量的 AMP, ADP, ATP, $\mathrm{H}_{2} \mathrm{PO}_{4}^{-}, \mathrm{F}^{-}, \mathrm{Cl}^{-}$, $\mathrm{Br}^{-}, \mathrm{CH}_{3} \mathrm{CO}_{2}^{-}, \mathrm{NO}_{3}^{-}, \mathrm{HCO}_{3}^{-}, \mathrm{ClO}_{4}^{-}$等离子均不能使 其颜色发生变化. 探针 10 不仅对 $\mathrm{PPi}$ 具有较高的亲和性 及较好的选择性, 而且在较宽的 $\mathrm{pH}$ 范围都表现出稳定 的苂光性质, 是一个具有较好实际应用前景的 PPi 苂光 和比色探针.

Hong 等 ${ }^{[18]}$ 设计合成了以 2-菜为荧光团, 酚氧基团 桥连双 DPA- $\mathrm{Zn}^{2+}$ 识别基团的 PPi 荧光探针 11. 该探针

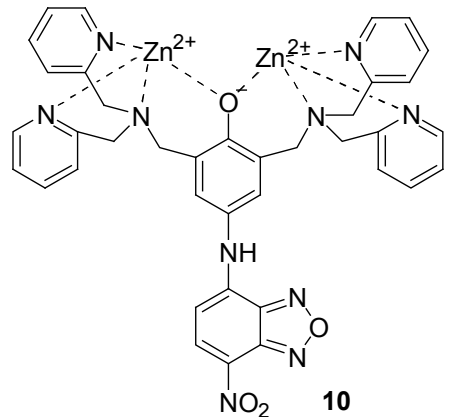

在较宽的 $\mathrm{pH}$ 范围内对 PPi 具有高的选择性. 在 $\mathrm{pH} 7.4$ 的纯水中, 探针 11 对 PPi 的选择性为 ATP 的 40 倍, 即 使在 100 当量其他常见阴离子存在的情况下，也不影响 其对 PPi 的定量检测. 此外, 在多种阴离子存在时, 只 有 PPi 可以诱导探针 11 最大荧光发射波长出现 $20 \mathrm{~nm}$ 的红移.

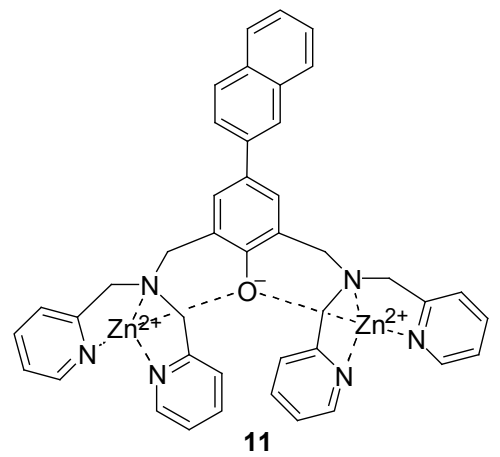

Aha 等 ${ }^{[19]}$ 报道了一系列结构相似且含有 DPA 基团 的荎甲腈衍生物苂光探针 12a, 12b 和 12c. 探针 12a 在 水溶液中对 PPi 表现出较强的苂光增强效应(17 倍), ATP 仅使苂光有微弱增强, 其他阴离子如 ADP, $\mathrm{H}_{2} \mathrm{PO}_{4}^{-}, \mathrm{HSO}_{4}^{-}, \mathrm{CH}_{3} \mathrm{COO}^{-}, \mathrm{F}^{-}, \mathrm{Cl}^{-}$等几乎不会引起荧 光信号的变化. 通过荧光滴定测得探针 12a 与 PPi 的结 合常数为 $1.0 \times 10^{5} \mathrm{~L} \cdot \mathrm{mol}^{-1}$. 与 $\mathbf{1 2 a}$ 相比, 探针 $\mathbf{1 2 b}$ 对 PPi 的选择性更好, ATP 及其他阴离子都几乎不影响其 荧光性质. 探针 $12 \mathrm{c}$ 与前两个探针相比对 PPi 的选择性 和灵敏度均有所下降. 有趣的是探针 $12 \mathrm{a}$ 和探针 $12 \mathrm{~b}$ 都 表现出时间依赖的苂光增强效应, 这可能是因为酚氧原 子与金属离子的配位键缓慢断裂造成的; 而探针 $12 \mathrm{c}$ 没 有酚氧基团，因而并不表现出时间依赖的荧光增强性 质.

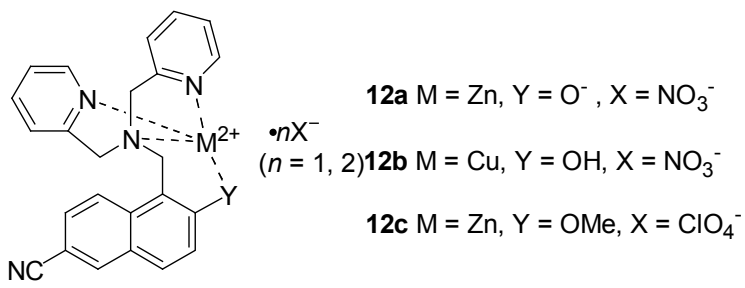


Tuck 等 ${ }^{[20]}$ 将 1-荎和 9-葱作为荧光团引入经典酚氧 骨架的双核 $\mathrm{DPA}-\mathrm{Zn}^{2+}$ 络合物中, 设计合成了 $\mathrm{PPi}$ 苂光探 针 13a 和 13b. 探针 13a 与 Hong 组的探针 11 类似, PPi 可使其荧光强度显著增强; 而探针 13b 却在 PPi 的存在 下荧光几乎完全淬灭. 这种差别可能是因为探针 $13 \mathrm{~b}$ 与 PPi 络合后, 葱较大的芳香环平面采取与苯环相垂直的 取向, 破坏了其与酚氧骨架的共轭, 增强了 DPA 上氮原 子孤对电子到葱苂光团的 PET 效应, 从而导致其荧光淬 灭.

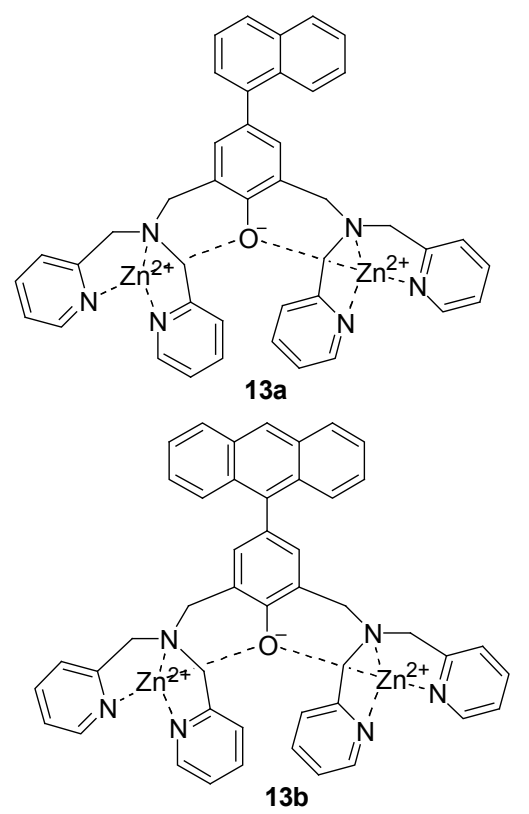

Hong 等 ${ }^{[21]}$ 设计并合成了以苯并氮硫杂茂为苂光团, DPA- $\mathrm{Zn}^{2+}$ 为识别基团的 PPi 荧光传感器 14. 该探针具有 吸收波长较长, 发射波长位于可见光区, 无毒, 细胞渗 透性好等优点. 在纯水中, PPi 存在下其荧光辐射显著提 高, 同时伴随着颜色由黄色变为褐色的过程, 可以实现 PPi 的苂光和比色检测. 该探针可以应用于活细胞的苂 光显像, 不足之处是 ATP 的存在对 PPi 的检测有一定的 干扰.

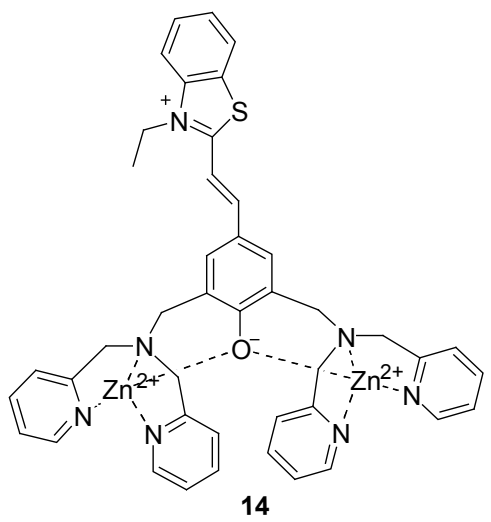

Tian 等 ${ }^{[22]}$ 将 DPA 连接到与苯并吡喃腈衍生物相共
轭的苯环上，与铜离子配位后形成了一个灵敏度较高、 选择性较好的 PPi 荧光传感器 $\mathbf{1 5}$. 在该传感器中, $\mathrm{DPA}-\mathrm{Cu}^{2+}$ 单元充当电子给体, 苯并吡喃做为电子受体, 当探针分子以合适的波长激发时, 会发生从 $\mathrm{DPA}-\mathrm{Cu}^{2+}$ 到苯并吡喃的分子内电荷转移(ICT) 过程. 将 $\mathrm{F}^{-}, \mathrm{Cl}^{-}$, $\mathrm{Br}^{-}, \mathrm{I}^{-}, \mathrm{H}_{2} \mathrm{PO}_{4}^{-}, \mathrm{HCO}_{3}^{-}, \mathrm{HSO}_{4}^{-}, \mathrm{CH}_{3} \mathrm{COO}^{-}, \mathrm{NO}_{3}^{-}$, $\mathrm{HPO}_{4}^{2-}, \mathrm{SO}_{4}^{2-}, \mathrm{CO}_{3}^{2-}, \mathrm{PO}_{4}^{3-}, \mathrm{PPi}$ 等分别加入探针 15 的溶液中, 仅 PPi 与其形成稳定的 $1: 1$ 络合物. 由于 $\mathrm{PPi}$ 的配位作用削弱了 $\mathrm{DPA}-\mathrm{Cu}^{2+}$ 络合单元中心铜离子 的拉电子能力, 相应地, DPA 的供电子能力增强, 使得 探针的 ICT 过程明显增强，导致其吸收波长红移，650 $\mathrm{nm}$ 处的荧光发射强度大为增加. 做为一种潜在的荧光 增强型近红外苂光传感器, 探针 15 被成功地应用于活 细胞中 PPi 的苂光成像.

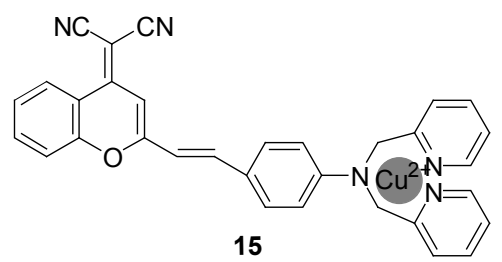

Yang 等 ${ }^{[23]}$ 将 DPA 连接在含有半菁结构单元的螺苯 并吡喃环上, 在锌离子的诱导下, 螺吡喃开环, 酚氧原 子参与锌离子的配位, 得到了一个比率型 PPi 苂光传感 器 16 (Scheme 1). 当向探针 16 的乙醇-水 $(V: V=1: 1)$ 溶液中加入 PPi 时, $620 \mathrm{~nm}$ 的荧光发射强度降低, 而 560 $\mathrm{nm}$ 的荧光发射增强，且两波长处的荧光强度之比与 PPi 浓度成正比，从而实现了探针 $\mathbf{1 6}$ 对 PPi 的比率型荧光检 测. 该探针对 PPi 的选择性高, 生物相关的含磷阴离子 的干扰较小, 对 PPi 的检测限为 $4.0 \times 10^{-7} \mathrm{~mol} / \mathrm{L}$. 另外, 探针 16 还实现于尿样中 PPi 的测定，作为一种简便易行 的方法, 具有一定的实际应用潜力.

我们研究组 ${ }^{[24]}$ 最近报道了基于 2 -氨基苯甲酰胺骨 架，以咔唑为荧光团、 BPEA- $\mathrm{Zn}^{2+}$ 络合单元为识别基团 的荧光探针 17. 利用氢键和金属络合协同作用实现了 探针 17 与 $\mathrm{PPi}$ 的高效结合, 结合常数约为 $2.5 \times 10^{10}$ $(\mathrm{mol} / \mathrm{L})^{-2}$. 加入 0.5 equiv. 的 PPi 可使其苂光强度大为增 加(43 48 倍); 其他阴离子除 ATP 和 ADP 可以诱导 6-12 倍荧光增强外, $\mathrm{F}^{-}, \mathrm{Br}^{-}, \mathrm{I}^{-}, \mathrm{Cl}^{-}, \mathrm{HCO}_{3}^{-}$, $\mathrm{CH}_{3} \mathrm{CO}_{2}^{-}, \mathrm{SO}_{4}^{2-}, \mathrm{NO}_{3}^{-}, \mathrm{C}_{2} \mathrm{O}_{4}^{2-}, \mathrm{H}_{2} \mathrm{PO}_{4}^{-}, \mathrm{CO}_{3}^{2-}$, $\mathrm{HPO}_{4}^{2-}$ 等均不引起苂光信号的变化. 通过氢键和金属 络合协同作用，探针 17 实现了水溶液中 PPi 的高选择性 和高灵敏度检测.

另外, Hong 研究组 ${ }^{[25]}$ 报道了以四苯基乙烯为荧光 团, DPA- $\mathrm{Zn}^{2+}$ 为受体的 PPi 荧光探针 18. 在水-DMSO $(V: V=10: 1)$ 溶液中, 等物质的量的 $\mathrm{PPi}$ 可引起探针 


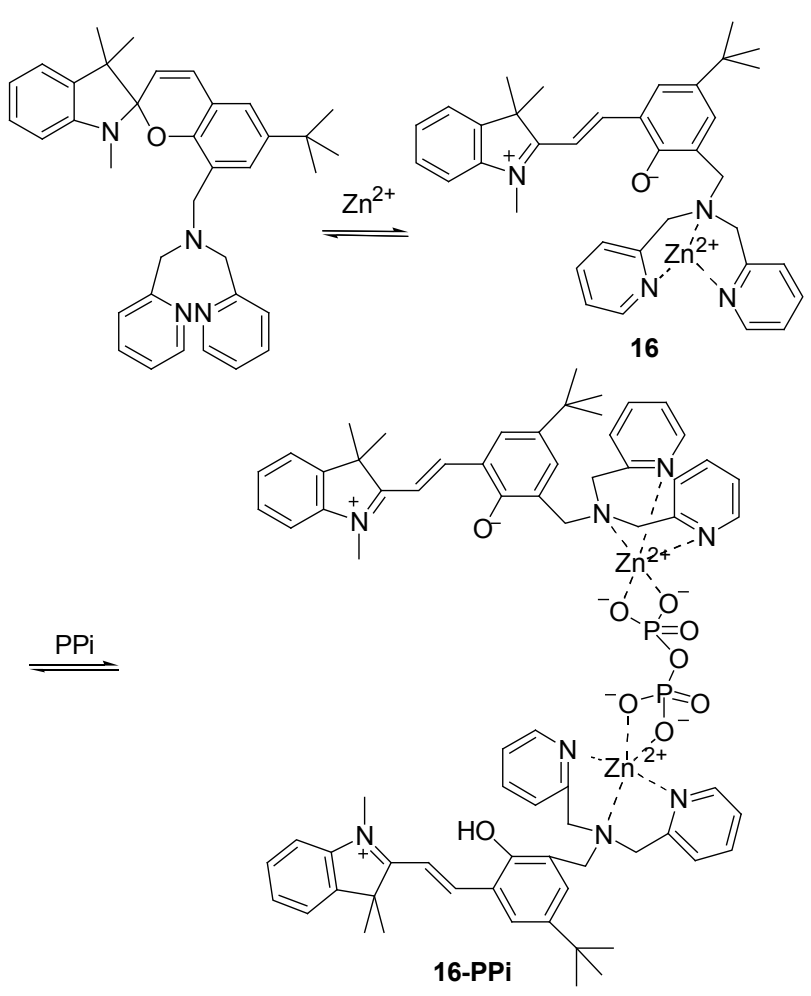

Scheme 1

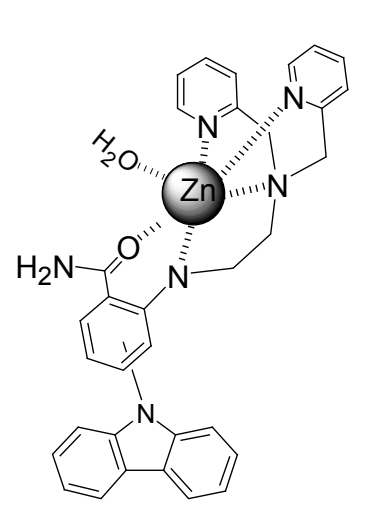

17

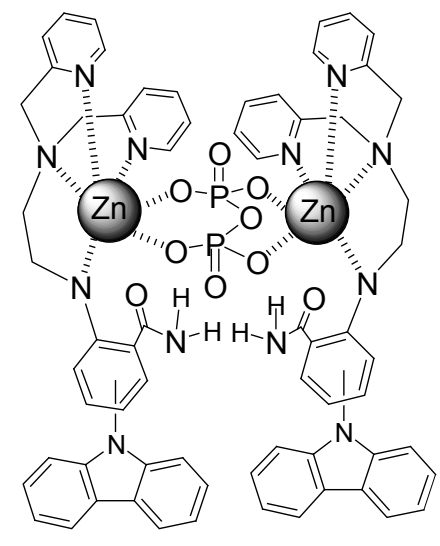

17-PPi

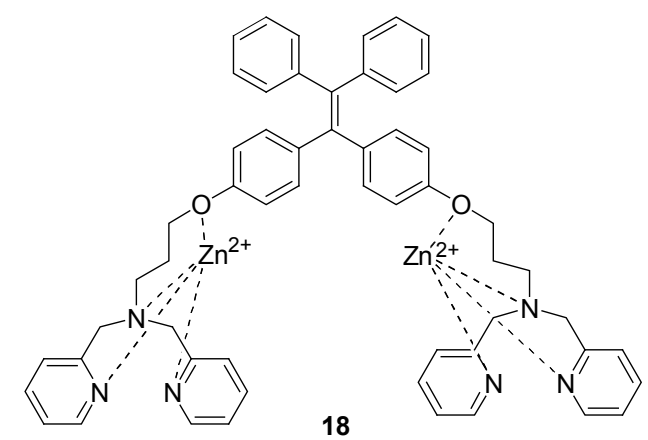

18 的苂光信号增强约 11 倍. 其荧光机制可能是由于 PPi 与 $\mathrm{DPA}-\mathrm{Zn}^{2+}$ 的络合限制了荧光团中苯环的自由旋转, 从而抑制了 PET 效应导致荧光发射的增强. 值得注意的
是, 相同当量的 ATP, AMP也可使探针 18 的荧光强度增 加 3 5 倍. 因此, 探针 18 对含磷阴离子的选择性较弱, 限制了其进一步的应用.

如上所述, 基于 $\mathrm{DPA}-\mathrm{M}^{2+}$, 尤其是 $\mathrm{DPA}-\mathrm{Zn}^{2+}$ 作为 PPi 识别基团近几年来发展迅速. 一些基于 $\mathrm{DPA}-\mathrm{M}^{2+}$ 识 别基团的荧光探针已成功地应用于纯水或生物体系中 PPi 的检测. 除了以 DPA-M ${ }^{2+}$ 作为识别单元以外, 一些 其他多齿配体与金属离子配位形成的络合单元对 PPi 也 有较好的识别效果，下面对近来报道的部分代表性探针 作简要介绍.

Ghosh 等 ${ }^{[26]}$ 最近报道了一个基于喹啉荧光团的 PPi 苂光探针 19 , 其中喹啉既是荧光团又可以与锌离子配 位. 该探针以环已二胺为骨架通过两个相邻的氨基分别 连接一个喹啉基团组成一个四氮杂原子螯合中心，与锌 离子配位. 该探针具有良好的水溶性，与 PPi 结合后荧 光淬灭. 除 ATP 会使其荧光略微减弱外, $\mathrm{F}^{-}, \mathrm{Cl}^{-}, \mathrm{Br}^{-}$, $\mathrm{SO}_{4}^{2-}, \mathrm{HCOO}^{-}, \mathrm{CH}_{3} \mathrm{CO}_{2}^{-}, \mathrm{ClO}_{4}^{-}, \mathrm{H}_{2} \mathrm{PO}_{4}^{-}, \mathrm{HSO}_{4}^{-}$, AMP 等均不会诱导其荧光发生任何变化. 晶体结构表 明, 硝酸根的两个氧原子参与锌离子配位, 探针与 PPi 以 $2: 1$ 的模式配位形成一个以 PPi 为中心的夹心结构.

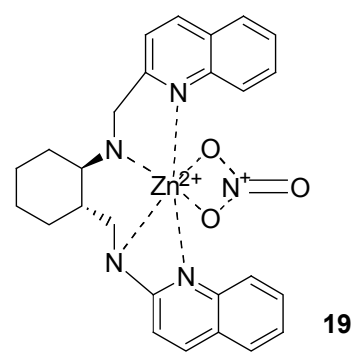

Qian 等 ${ }^{[27]}$ 报道了一个以多酰胺-镉离子为识别基 才, 氟硼荧为苂光团的 PPi 荧光探针 20 . 该探针具有吸 收和发射光谱位于近红外区、光稳定性好、量子产率高 和对体系 $\mathrm{pH}$ 值不敏感等优点. 探针 20 本身苂光较强, 络合 PPi 后荧光几乎完全淬灭; 相同条件下其他阴离子 如 AMP, ADP, ATP $, \mathrm{HCO}_{3}^{-}, \mathrm{F}^{-}, \mathrm{I}^{-}, \mathrm{Br}^{-}, \mathrm{SO}_{4}^{2-}$,

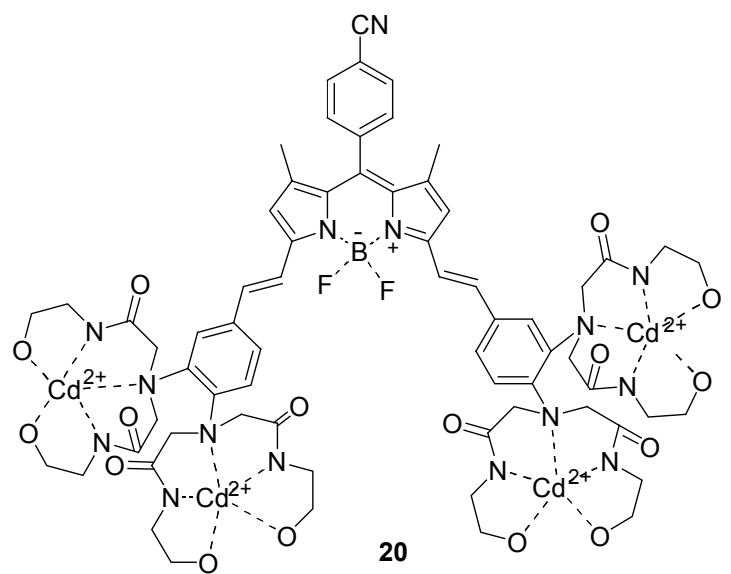


$\mathrm{CF}_{3} \mathrm{SO}_{3}^{-}, \mathrm{NO}_{3}^{-}, \mathrm{CH}_{3} \mathrm{CO}_{2}^{-}, \mathrm{H}_{2} \mathrm{PO}_{4}^{-}, \mathrm{HSO}_{4}^{-}, \mathrm{Cl}^{-}$等 均不会使其苂光强度发生变化, 从而实现了对 PPi 的选 择性识别.

总的来说, 近十几年来以 $\mathrm{DPA}-\mathrm{Zn}^{2+}$ (包括 BPEA- $\mathrm{Zn}^{2+}$ ) 作为受体的 PPi 探针发展最为迅速, 表 1 总 结了使用不同苂光团设计合成该类苂光探针的光谱数 据.

\section{2 基于激基缔合物识别}

当两个苂光团(如芘、芸酰亚胺和菜等)的空间距离 较近(一般 $<35 \mathrm{~nm}$ ) 时, 会存在 $\pi-\pi$ 堆积等弱的相互作用. 此时, 其中的一个苂光团受到激发后会与另外一个处于 基态的苂光团形成激基缔合物, 从而在荧光发射光谱上 同时呈现短波长区的单体发射峰和长波区的激基缔合 物发射峰.

Hong 等 ${ }^{[28]}$ 将萠苂光团与 DPA- $\mathrm{Zn}^{2+}$ 识别单元相连 接得到苂光探针 21. 该探针在 0.3 equiv. PPi 的诱导下呈 现出一个较强的萠激基缔合物荧光发射峰, 探针和 PPi 的络合比 $2: 1$. 继续滴加 PPi 荧光强度有所减弱, 可能 存在探针和 PPi 络合比 $1: 1$ 络合平衡的竞争. 0.3 equiv.
ATP 诱导探针 21 产生一个较弱的激基缔合物荧光发射 峰, 过量的 ATP 存在下该发射峰消失. 因此, 探针 21 可 以在过量 ATP 存在下高效检测 PPi. 而其他阴离子 AMP, $\mathrm{F}^{-}, \mathrm{NO}_{3}^{-}, \mathrm{AcO}^{-}, \mathrm{HPO}_{4}^{2-}, \mathrm{HSO}_{4}^{-}, \mathrm{Cl}^{-}$等不能 诱导探针 21 产生任何荧光性质的变化. 对于 $\mathrm{PPi}$ 较之于 ATP 的高选择性可能是因为 ATP 分子中参与络合的四 个磷氧原子的总电荷密度比 PPi 低.

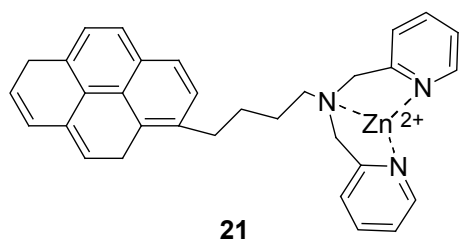

在此基础上, Hong 等 ${ }^{[29]}$ 又设计合成了酚氧桥连双 $\mathrm{DPA}-\mathrm{Zn}^{2+}$ 络合单元为受体的 PPi 荧光探针 22. 该探针同 样以萠为荧光团, 对 PPi 和 ATP 均具有较高的灵敏度, 仅 0.24 equiv. 的 PPi 或 ATP 即可诱导激基缔合物荧光发 射峰出现 $92 \%$ 的淬灭, 而其他阴离子如 $\mathrm{ADP}, \mathrm{H}_{2} \mathrm{PO}_{4}^{-}$ 等对其苂光性质均没有响应. 探针 22 与 PPi 及 ATP 的 络合常数未见报道, 对 ATP 和 PPi 的选择性较差.

表 1 采用 DPA- $\mathrm{Zn}^{2+}$ 作为识别基团的 PPi 探针

Table 1 The PPi probe with DPA- $\mathrm{Zn}^{2+}$ as receptors

\begin{tabular}{|c|c|c|c|c|c|c|c|}
\hline 化合物 & 苂光团 & 探针类型 & $\lambda_{\mathrm{ex}} / \lambda_{\mathrm{max}, \mathrm{abs}} / \mathrm{nm}$ & $\lambda_{\max , \mathrm{em}} / \mathrm{nm}$ & $K_{\mathrm{d}}$ & 检测体系 & 测定 $\mathrm{pH}$ 值 \\
\hline 1 & 偶氮酚 & 比色 & 465 & - & $1.5 \mathrm{nmol} \cdot \mathrm{L}^{-1}$ & $10 \mathrm{mmol} \cdot \mathrm{L}^{-1} \mathrm{HEPES}$ & 7.4 \\
\hline 2 & 荧光素 & 比率 & 517 & 523,534 & $10.2 \mu \mathrm{mol} \cdot \mathrm{L}^{-1}$ & $20 \mathrm{mmol} \cdot \mathrm{L}^{-1} \mathrm{HEPES}$ & 7.4 \\
\hline 3 & 呋啶 & On-off & 359 & 462,442 & $21 \mathrm{nmol} \cdot \mathrm{L}^{-1}$ & $10 \mathrm{mmol} \cdot \mathrm{L}^{-1} \mathrm{HEPES}$ & 7.4 \\
\hline 4 & 苯并噁唑 & 比率 & 365 & 420,518 & $10.9 \mathrm{nmol} \cdot \mathrm{L}^{-1}$ & $10 \mathrm{mmol} \cdot \mathrm{L}^{-1} \mathrm{HEPES}$ & 7.4 \\
\hline $5 \mathbf{b}$ & 香豆素 & Off-on & 393 & 475 & $76 \mu \mathrm{mol} \cdot \mathrm{L}^{-1}$ & $20 \mathrm{mmol} \cdot \mathrm{L}^{-1} \mathrm{HEPES}$ & 7.4 \\
\hline $6 a$ & 香豆素 & On-off & 328 & 425 & $3.1 \mu \mathrm{mol} \cdot \mathrm{L}^{-1}$ & $10 \mathrm{mmol} \cdot \mathrm{L}^{-1} \mathrm{HEPES}$ & 7.4 \\
\hline 7 & 香豆素 & On-off & - & 520 & - & $10 \mathrm{mmol} \cdot \mathrm{L}^{-1} \mathrm{HEPES}$ & 7.4 \\
\hline 8 & 萗酰亚胺 & On-off & 360 & 505,481 & - & $\begin{array}{l}20 \mathrm{mmol} \cdot \mathrm{L}^{-1} \mathrm{HEPES} \\
5 \% \mathrm{CH}_{3} \mathrm{CN}\end{array}$ & 7.4 \\
\hline 9a & 苯并噁二唑 & Off-on & 468 & 591 & $3.6 \mu \mathrm{mol} \cdot \mathrm{L}^{-1}$ & $\begin{array}{l}10 \mathrm{mmol} \cdot \mathrm{L}^{-1} \mathrm{HEPES}, \\
3 \% \mathrm{DMSO}\end{array}$ & 7.2 \\
\hline 10 & 苯并噁二唑 & 比色 & 526 & - & $3.3 \mathrm{nmol} \cdot \mathrm{L}^{-1}$ & $50 \mathrm{mmol} \cdot \mathrm{L}^{-1} \mathrm{HEPES}$ & 7.4 \\
\hline 11 & 2-䓺 & Off-on & 305 & 436,456 & $3.4 \mathrm{nmol} \cdot \mathrm{L}^{-1}$ & $10 \mathrm{mmol} \cdot \mathrm{L}^{-1} \mathrm{HEPES}$ & 7.4 \\
\hline $12 a$ & 䓺甲腈 & Off-on & 310 & 435 & $10 \mu \mathrm{mol} \cdot \mathrm{L}^{-1}$ & $10 \mathrm{mmol} \cdot \mathrm{L}^{-1} \mathrm{HEPES}$ & 7.4 \\
\hline $13 a$ & 1-萘 & Off-on & 310 & 464 & $1.4 \mu \mathrm{mol} \cdot \mathrm{L}^{-1}$ & $10 \mathrm{mmol} \cdot \mathrm{L}^{-1}$ Tris & 7.5 \\
\hline $13 b$ & 9-蒽 & On-off & 370 & 484 & $0.83 \mu \mathrm{mol} \cdot \mathrm{L}^{-1}$ & $10 \mathrm{mmol} \cdot \mathrm{L}^{-1}$ Tris & 7.5 \\
\hline 14 & 苯并氮硫杂茂 & Off-on & 500 & 560 & $22 \mathrm{nmol} \cdot \mathrm{L}^{-1}$ & $10 \mathrm{mmol} \cdot \mathrm{L}^{-1} \mathrm{HEPES}$ & 7.4 \\
\hline 15 & 苯并吡喃腈 & Off-on & 447 & 650 & $2.2 \mu \mathrm{mol} \cdot \mathrm{L}^{-1}$ & $\begin{array}{l}\text { ethanol/water } \\
(V: V=6: 4)\end{array}$ & 7.0 \\
\hline 16 & 螺吡喃 & 比率 & 522 & 560,620 & $4.2 \mathrm{n}\left(\mathrm{mol} \cdot \mathrm{L}^{-1}\right)^{2}$ & $\begin{array}{l}\text { ethanol/water } \\
(V: V=3: 7)\end{array}$ & 7.4 \\
\hline 17 & 咔唑 & Off-on & 350 & 428 & $0.04 \mathrm{n}\left(\mathrm{mol} \cdot \mathrm{L}^{-1}\right)^{2}$ & $10 \mathrm{mmol} \cdot \mathrm{L}^{-1} \mathrm{HEPES}$ & 7.4 \\
\hline 18 & 四苯乙烯 & Off-on & 320 & 472 & - & $\begin{array}{l}\mathrm{H}_{2} \mathrm{O} / \mathrm{DMSO} \\
(V: V=10: 1)\end{array}$ & - \\
\hline 19 & 喹啉 & On-off & 315 & 376 & $2.1 \mu\left(\mathrm{mol} \cdot \mathrm{L}^{-1}\right)^{2}$ & $10 \mathrm{mmol} \cdot \mathrm{L}^{-1} \mathrm{HEPES}$ & 7.4 \\
\hline 20 & 氟嗍荧 & On-off & 620 & 637 & - & $\begin{array}{l}\mathrm{CH}_{3} \mathrm{CN} / \text { water } \\
(V: V=1: 20)\end{array}$ & - \\
\hline
\end{tabular}




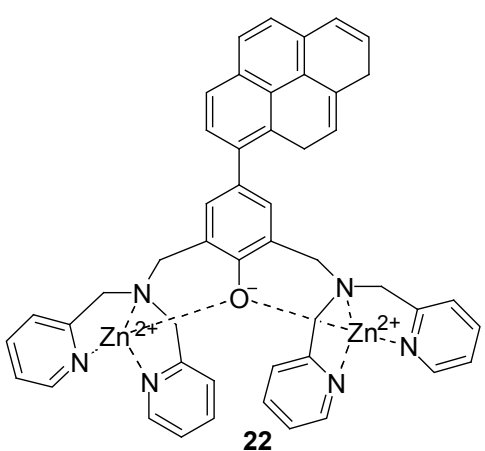

2007 年, Yoon 等 ${ }^{[30]}$ 报道了以荎酰亚胺衍生物为苂 光团, $\mathrm{DPA}-\mathrm{Zn}^{2+}$ 络合单元为识别基团的 PPi 荧光传感器 23. 通过两个 PPi 分子与四个锌离子络合以及萗环间的 $\pi-\pi$ 堆积作用, 探针 23 与 PPi 组装成结构独特的 $2+2$ 型复合物 23-PPi, 在 $490 \mathrm{~nm}$ 处出现特征的激基缔合物 荧光发射峰. 探针 23 对 PPi 具有较好的识别能力, 其他 阴离子包括 ADP 等均不能导致上述荧光信号的变化, 实现了在纯水溶液中对 PPi 的高效识别.

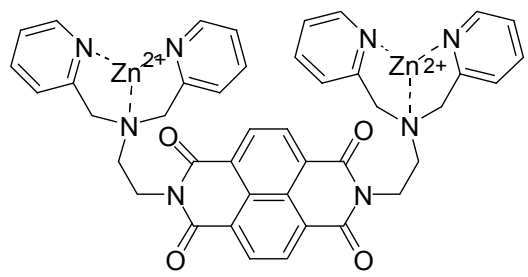

23

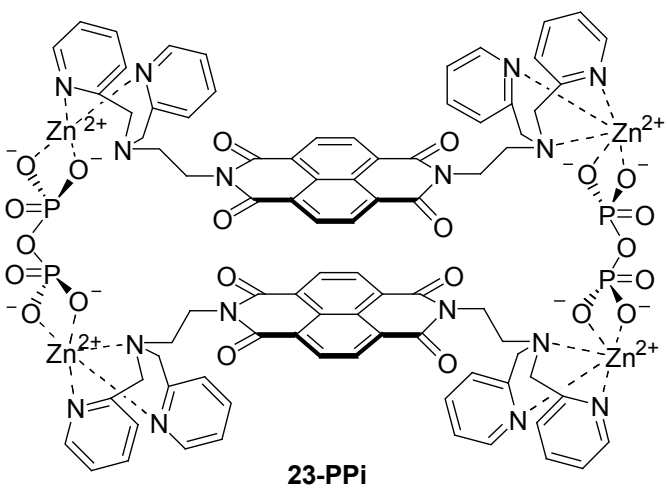

2011 年, Wang 等 ${ }^{[31]}$ 报道了一个以萗为苂光团, 大 环多胺 $-\mathrm{Zn}^{2+}$ 络合单元为识别基团的 PPi 苂光传感器 24 . 该探针对 PPi 具有较高的亲和性和选择识别能力. 在 PPi 配位与菜环 $\pi-\pi$ 堆积的共同作用下, 探针 24 与 PPi 组装形成以一分子 PPi 为中心两分子探针化合物为夹层 的三明治结构 24-PPi, 探针 24 与 PPi 的络合比为 2:1, 经测得其结合常数为 $2.1 \times 10^{8}(\mathrm{~mol} / \mathrm{L})^{-2}$. 其他含磷阴离 子如 ATP, ADP, AMP 等均不能诱导其形成激基缔合物, 从而实现了对 PPi 的高选择性识别. 随着 PPi 的加入, 在 $415 \mathrm{~nm}$ 处特征激基缔合物荧光发射峰逐渐升高，同时
$337 \mathrm{~nm}$ 处荎环特征单体峰降低. 通过 $I_{415} / I_{337}$ 的菼光强 度比值可以实现 PPi 的比率检测. 探针 $\mathbf{2 4}$ 也成功地被应 用于无机焦磷酸酶活性的实时监测.
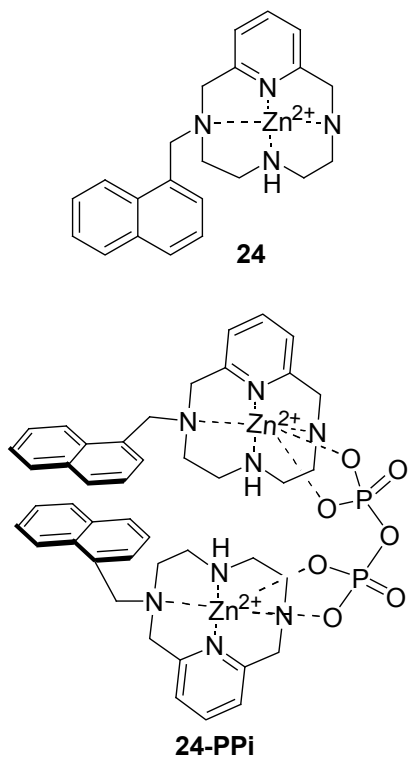

\section{3 基于荧光指示剂置换}

一些金属络合物缺乏有效的荧光团作为信号报告 单元，荧光指示剂竞争置换成为其有效检测被分析物而 广泛使用的传感策略. 荧光竞争置换模式也包含受体和 信号单元，受体为金属络合物，信号单元为荧光指示剂， 二者之间为非共价键合，即二者通过配位作用形成 “化 学传感体系(chemosensing ensemble)”。当被分析物介 入这种化学传感体系并通过竞争置换方式与受体结合 后，信号单元被重新游离到溶液中，恢复了未配位时的 波谱特征. 若信号单元在化学传感体系中和游离状态下 的波谱性质不同，则被分析物(如阴离子)与受体结合后 将伴随有苂光信号的变化. 如果受体和信号单元之间的 络合常数比其与被分析物之间的络合常数小，就能够实 现基于苂光指示剂置换的高效苂光识别与传感.

2002 年 Kim 等 ${ }^{[32]}$ 首次报道了基于荧光指示剂置换 策略, DPA- $\mathrm{Zn}^{2+}$ 络合物 25 担当受体的化学传感体系. 该 化合物与荧光指示剂 PV 组成 $1: 1$ 的配合物实现了水溶 液中菼光及比色检测磷酸根. 之后该组又发现，该传感 体系在 cAMP 存在下对 AMP 具有较高的选择性和灵敏 度, 已经被成功用于研究 cAMP 的水解反应 ${ }^{[33]}$. Smith 等 ${ }^{[34]}$ 在此研究基础上发现该化合物 25 与香豆素甲基磺 酸苂光染料(CS)组成新的传感体系，可以对 PPi 进行有 效的识别, 选择性为 $\mathrm{HPO}_{4}^{2-}$ 的 60 倍. 另外, 他们 ${ }^{[34]}$ 还 发现比化合物 25 结构更为简单的化合物 26 也可与 CS 组成有效的传感体系实现对 PPi 的选择性检测. 


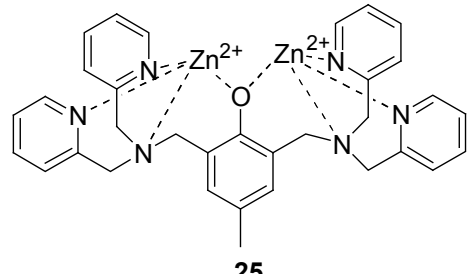

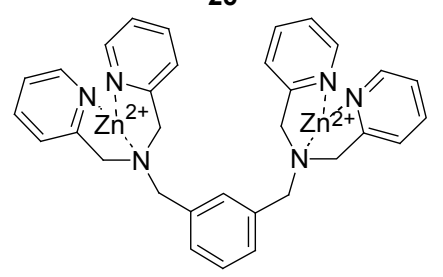

26

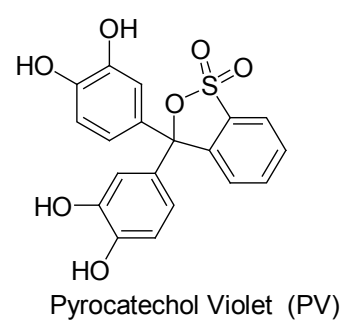<smiles>O=c1cc(CS(=O)(=O)[O-])c2cc(O)c(O)cc2o1</smiles>

CS

另外, Smith 等 ${ }^{[35]}$ 还笁选了 11 种苂光指示剂与化合 物 25 的相互作用, 研究表明它们的解离常数分布在 $2.8 \times 10^{-4}$ 到 $2.7 \times 10^{-6} \mathrm{~mol} / \mathrm{L}$ 之间. 横跨两个数量级的 亲和性差别可能是由于指示剂的立体构型和所带电荷 不同所致. 最终研究表明 BPR, MB9, ZC 作为指示剂可 以实现对 PPi 的选择性检测.<smiles>O=S1(=O)Oc2c(cc(Br)c(O)c2Br)C2(O1)c1cccc(O)c1Oc1c2cc(Br)c(O)c1O</smiles>

Bromo Pyrogallol Red (BPR)

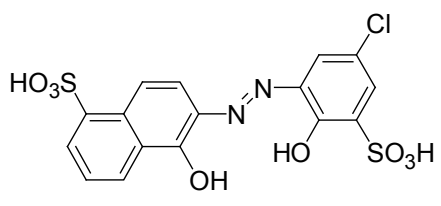

Mordant Blue 9 (MB9)<smiles>O=C(O)c1ccccc1N/N=C(/N=Nc1cc(S(=O)(=O)O)ccc1O)c1ccccc1</smiles>

Zincon $(\mathrm{ZC})$

作为化合物 25 的拓展, Hong 等 ${ }^{[36]}$ 在其 DPA 单元上 引入了四个乙酰胺基作为氢键的给体设计合成了 PPi 探 针 27. 通过紫外滴定测得该探针在 HEPES 缓冲溶液中 与 PV 和 PPi 的结合常数分别为 $1.4 \times 10^{5}$ 和 $5.39 \times 10^{10}$ $\mathrm{L} \cdot \mathrm{mol}^{-1}$. 该探针与 PPi 高的亲和性归功于金属络合效应 和氢键络合效应的协同作用, $\mathrm{X}$ 射线单晶衍射结果很好 地证实了这一推测. 但是该探针与其他磷酸腺苷的结合
数据并没有报道, 其选择性仍有待于进一步证实.

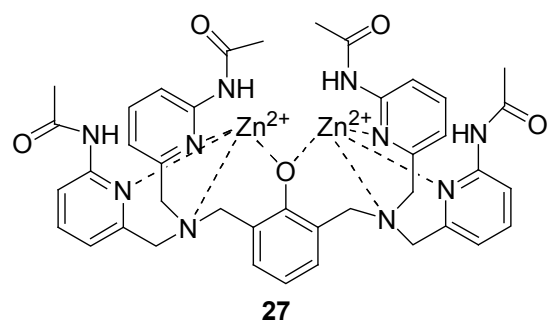

近来, Feng 等 ${ }^{[37}$ 设计合成了烷氧桥连双 DPA 锌离 子络合中心, DPA 上四个吡啶环上分别为无取代, 氨基 取代，乙酰氨基取代的络合物 $\mathbf{2 8 a} \sim 28 \mathrm{c}$. 该络合物均可 与 PV 形成 $1: 1$ 的化学传感体系. 作为对照, 无氢键给 体的络合物 28a 检测 PPi 时, 受到柠檬酸根的干扰; 而 化合物 28b, 28c 由于存在多重氢键和锌离子对 PPi 的协 同作用，克服了上述干扰.上述研究再次证实氢键和金 属离子络合协同效应对 PPi 高选择性识别具有促进作 用.

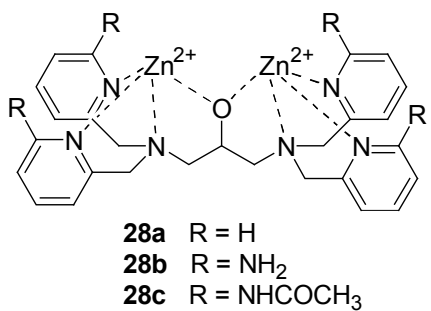

Vilar 等 ${ }^{[38]}$ 报道了一个以稀土金属钝螯合物为母 体，两个 DPA- $\mathrm{Zn}^{2+}$ 单元为受体臂的化合物 29. 该化合 物可与 PV 组成 PPi 化学传感体系. 生理条件下, 当 PPi 加入该体系, 溶液颜色由蓝色变为黄色, 实现了 PPi 的 比色置换检测. 研究还发现，该传感体系与 PPi 强的络 合作用能增强钝螯合物的弛豫效能. 因此，通过与 PPi 的有效络合能显著提高化合物 29 的核磁共振显像性能. 不足之处是该传感器对 PPi 和 ATP 的区分性不好, 因此 其实际应用受到一定限制.

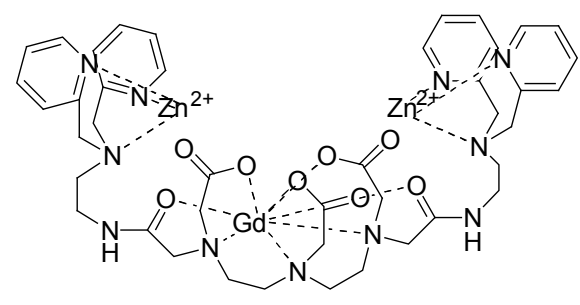

29

Kubo 及其合作者 ${ }^{[39]}$ 成功设计了以 BPEA- $\mathrm{Zn}^{2+}$ 苯硼 酸化合物 30 为受体，茜素红指示剂(ARS)为报告基团的 PPi 化学传感器. 首先, 体系中不含 PPi 时, 指示剂 ARS 通过与受体化合物中的 BPEA- $\mathrm{Zn}^{2+}$ 单元络合而发射弱 
的苂光. 加入 PPi 后, 茜素红被置换出来继而与受体中 的嗍酸基团成酯, 同时苂光辐射增强. 受体化合物 $\mathbf{3 0}$ 与 PPi, ATP, ADP 的络合常数分别为 $1.6 \times 10^{6}, 1.6 \times 10^{5}$,

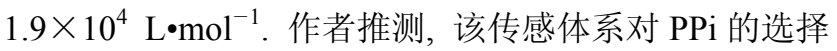
性识别可能是由于受体与不同的含磷阴离子成键时磷 氧原子的总电荷密度不同所导致.
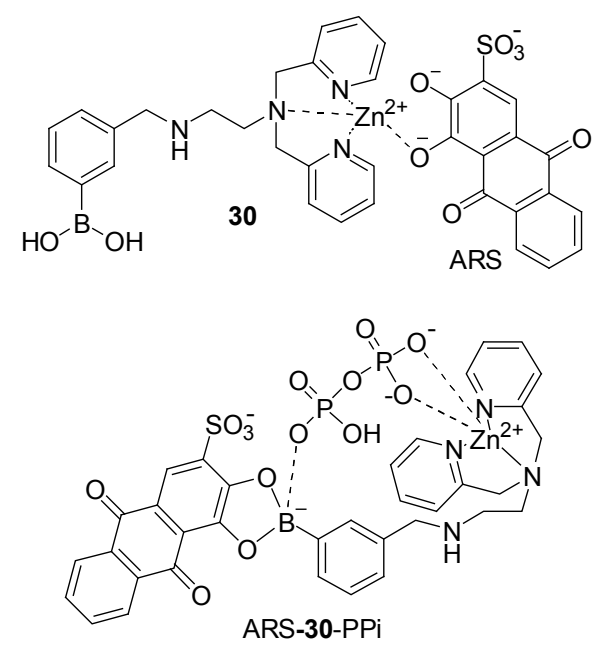

Jolliffe 及其合作者 ${ }^{[40 \sim 42]}$ 报道了一系列结构相似的 PPi 受体 31 36. 它们均以噁唑修饰的大环酰胺为骨架, DPA- $\mathrm{Zn}^{2+}$ 单元为受体臂. 刚性的大环酰胺骨架可以有 效束缚两个锌离子络合中心之间的空间距离, 更有利于 其与 PPi 匹配络合. 实际上, 在 HEPES 缓冲液中, 探针 31 与 $\mathrm{PPi}$ 之间的络合常数高达 $1.0 \times 10^{8} \mathrm{~L} \cdot \mathrm{mol}^{-1}$, 是其他 磷酸腺苷如 ATP 和 ADP 的 100 倍. 通过 CS 与探针 31 形成的化学传感体系实现了对 PPi 的高选择性识别. 改 变 DPA- $\mathrm{Zn}^{2+}$ 受体臂的位置，使其彼此接近，探针 34,35 对 PPi 的选择性明显增加. 但是, 以二酮哌嗪为骨架的 探针 36 对 PPi 选择性显著降低, 这表明较大的环酰胺骨 架更有利于 PPi 的识别.

Hong 等 ${ }^{[43]}$ 报道了一个基于 “淬灭剂-受体” (Q-R) 和 “苂光指示剂-特定分析物(F-A)” 通过特定分析物 A 与受体 $\mathrm{R}$ 之间的弱相互作用力组合而成的 “苂光化学 传感体系” (Q-R/F-A, Eq. 1, Q 为偶氮化合物; $A$ 为含有 酚氧骨架和双 $D P A-Z^{2+}$ 单元的化合物; $F$ 为荧光素; $A$ 为 $\mathrm{Pi}$ 或 $\mathrm{PPi}$. 水溶液中由于淬灭剂偶氮化合物的存在, Q-R/F-Pi 络合物荧光较弱. 加入相对于 F-Pi 浓度 3 个当 量的 PPi, 即可将发射较强荧光的 F-Pi 完全置换出来, 检测体系的荧光强度增加 45 倍. 实验测得 PPi 和 ATP 与 $\mathrm{Q}-\mathrm{R}$ 之间的络合常数分别为 $\approx 10^{8} \mathrm{~L} \cdot \mathrm{mol}^{-1}$ 和 $<10^{7}$ $\mathrm{L} \cdot \mathrm{mol}^{-1}$. 3 equiv. 的 ATP 和 ADP 可使传感体系的苂光强 度增加 11 18 倍, 60 倍过量的 Pi 和 AMP 仅仅诱导体系 微弱的荧光改变 (5 倍荧光增强). 因此, 该传感体系对被 分析物的选择识别能力顺序为 $\mathrm{PPi}>\mathrm{ATP}>\mathrm{ADP}>$
$\mathrm{AMP} \approx \mathrm{Pi}>\mathrm{CH}_{3} \mathrm{CO}_{2}^{-} \approx \mathrm{F}^{-}$.
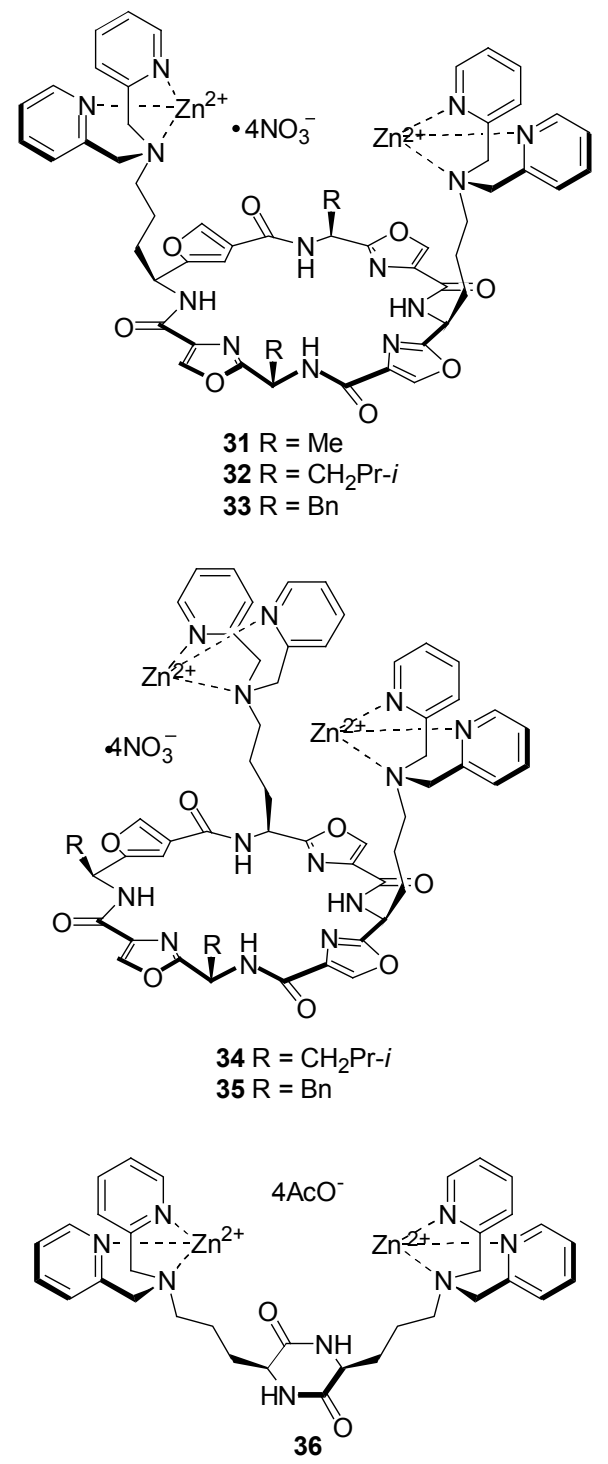

$\mathrm{He}$ 等 ${ }^{[44]}$ 设计了分别基于双核 $\mathrm{DPA}-\mathrm{Zn}^{2+}$ 的络合物 37 和基于双核 $\mathrm{DPA}-\mathrm{Cu}^{2+}$ 络合物 38. 它们均可以与 $\mathrm{PV}$ 组成化学传感体系, 对 PPi 具有较好的识别能力. 在 HEPES 缓冲液中, 通过紫外吸收滴定实验测得化合物 37 与 $\mathrm{PPi}$ 的络合常数为 $7.9 \times 10^{5} \mathrm{~L} \cdot \mathrm{mol}^{-1}$ ，与其他阴离子 如 ATP, ADP, AMP, Pi 等均表现出较弱的结合能力. 相 比之下, 化合物 38 与 $\mathrm{PPi}$ 的络合能力较弱 $\left(K_{\mathrm{a}}=862\right.$ $\left.\mathrm{L} \cdot \mathrm{mol}^{-1}\right)$ ，与其他阴离子几乎没有作用.

Lee 及其合作者 ${ }^{[45]}$ 最近报道了一个基于吡咯的大环 化合物 39 与香豆素衍生物荧光指示剂 40 组成的化学传 感体系, 该体系对 PPi 具有较好的选择性. 在乙腈溶液 中, 由于存在吡咯氮原子的孤对电子与苂光指示剂 40 之间的 PET 作用, [39.40]络合物的苂光几乎完全淬灭. 虽然化合物 39 与指示剂 40 之间存在静电和 $\pi-\pi$ 相互作 


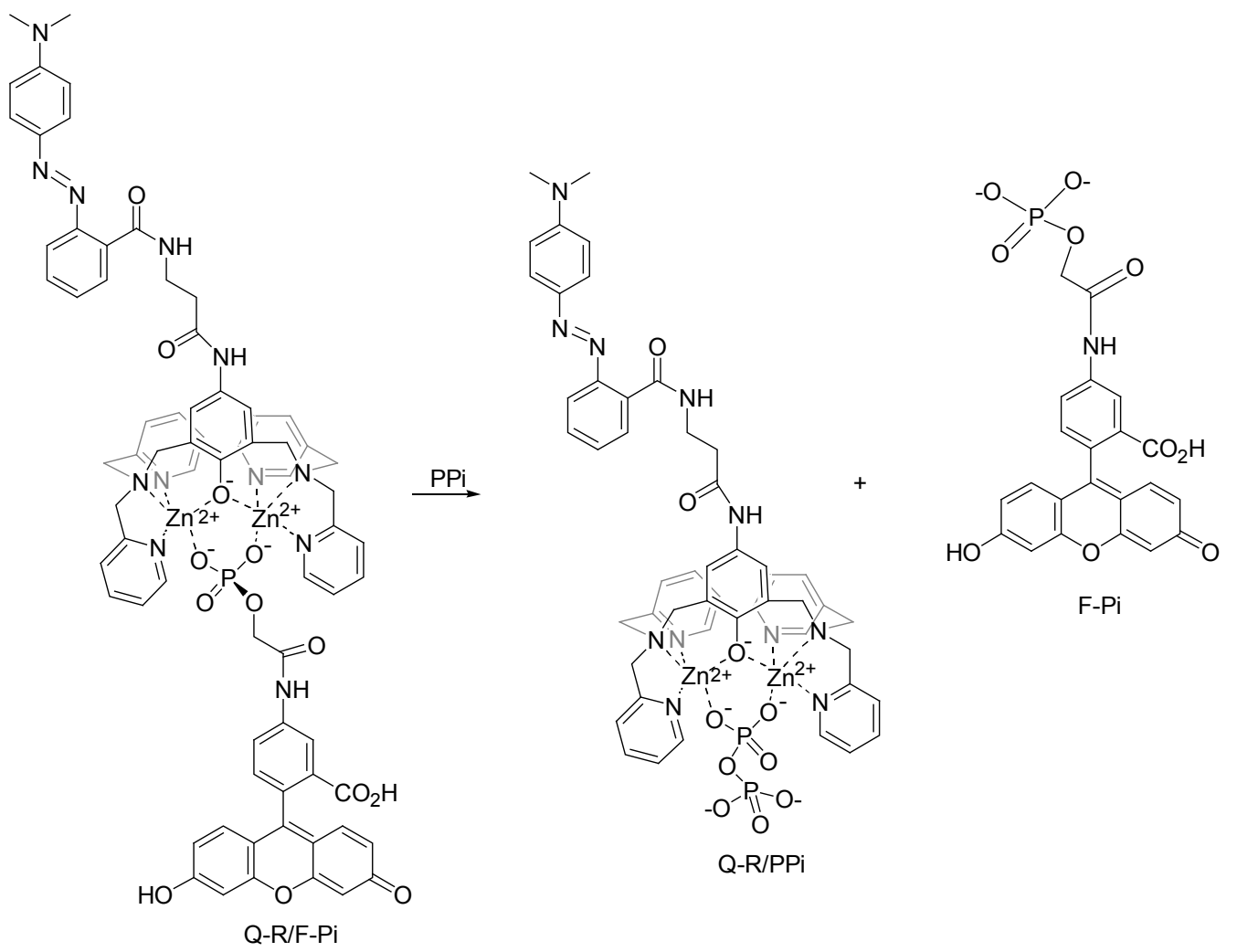

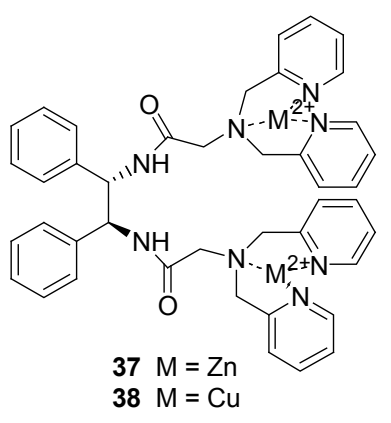

用，所形成的 $[39 \cdot 40]$ 络合物具有一定的稳定性; 但是 PPi 加入体系后, 可将指示剂 40 完全置换出来, 导致体 系的荧光辐射恢复 (Scheme 2). 化合物 1 对阴离子的亲 和性顺序大致为 $\mathrm{HP}_{2} \mathrm{O}_{7}^{3-}>\mathrm{F}^{-} \approx \mathrm{H}_{2} \mathrm{PO}_{4}^{-}, \mathrm{CH}_{3} \mathrm{COO}^{-} \approx$ $\mathrm{Cl}^{-}>\mathrm{HSO}_{4}^{-}, \mathrm{Br}^{-}$. 该检测体系对 $\mathrm{PPi}$ 较高的选择性可 以归结为多种因素相互协同作用的结果: 首先, 化合物 39 与 PPi 之间存在较强的静电相互作用; 其次, PPi 合适 的空间结构有效分散电荷分布, 且稳定阴离子- $\pi$ 相互作 用; 另外, 多重氢键的存在有效促进络合物的形成及其 稳定性.

Hong 等 ${ }^{[46]}$ 将两个 DPA-Cu${ }^{2+}$ 络合单元连接在苯环 的间位设计合成了一个简单的螯合物 41 , 将其分别与 PV 及苂光素组成化学传感体系, 均实现了水溶液中 PPi 的有效识别. 前者中, PV 溶液本身为黄色, 加入化合物 后溶液变为蓝色, 2 equiv. 的 PPi 使其重新变为黄色, 实

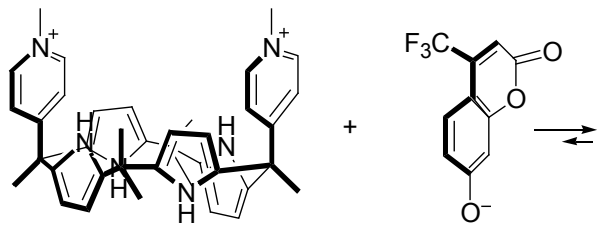

39

40

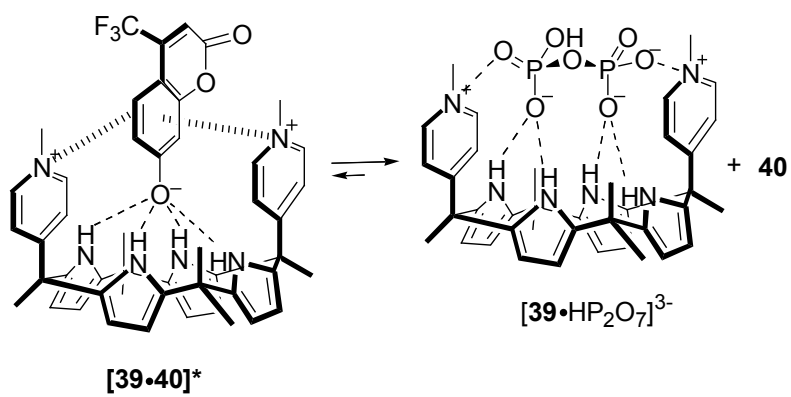

Scheme 2

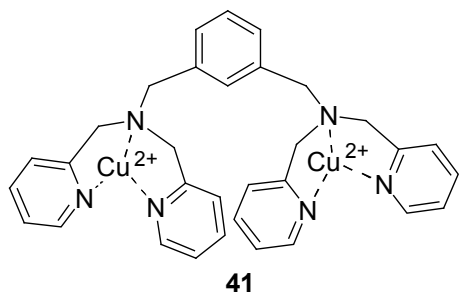

现了 PPi 的高效比色检测. ATP, ADP, AMP, Pi, $\mathrm{CH}_{3} \mathrm{COO}^{-}$, $\mathrm{NO}_{3}^{-}, \mathrm{F}^{-}, \mathrm{Cl}^{-}, \mathrm{I}^{-}$等均不会引起任何颜色变化. 后者中, 
化合物 41 将荧光素荧光淬灭, 加入 1.2 当量的 PPi 后, 体系的荧光发射增强 5.7 倍, 并达到饱和; 而 ATP, ADP, AMP, Pi 等分别使其苂光增强 3.6, 3.2, 2.0, 1.9 倍, 其他 阴离子则对传感体系的荧光性质几乎没有影响.

\section{4 基于静电或氢键作用识别}

基于静电或氢键作用的 PPi 荧光探针通常使用的识 别基团有酰胺、脲、吡咯等中性分子以及铵盐、胍盐、 咪唑鎓盐等, 与金属络合物识别相比, 该类荧光探针在 水溶液中对 PPi 的选择性较差, $\mathrm{F}^{-}, \mathrm{CH}_{3} \mathrm{COO}^{-}, \mathrm{CO}_{3}^{2-}$ 等 阴离子通常会干扰其检测. 但是, 从分子识别角度来看, 此类荧光探针在早期的 PPi 检测体系研究中具有十分重 要的地位, 对后来 PPi 荧光探针的发展具有重要的参考 价值. 下面对基于静电或氢键作用的 PPi 荧光探针做简 要介绍.

Teramae 等 ${ }^{[47]}$ 报道了一个基于萠单胍盐为识别基团 的 PPi 荧光探针 42, 在甲醇溶液中实现了对 PPi 的选择 性识别. 0.5 equiv. PPi 存在时, 探针 $\mathbf{4 2}$ 与 PPi 自组装形 成络合比为 $2: 1$ 的三明治结构复合物, 继续加入 $\mathrm{PPi}$ 则出现 $2: 1$ 和 $1: 1$ 的络合模式的平衡, 相应的结合常 数分别为 $1.2 \times 10^{8}$ 和 $1.0 \times 10^{4} \mathrm{~L} \cdot \mathrm{mol}^{-1}$.

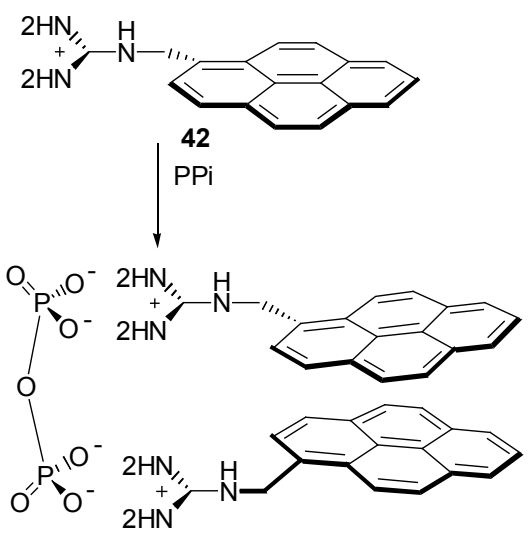

Yong 及其合作者 ${ }^{[48]}$ 报道了四个基于葱荧光团的咪 唑盐 PPi 荧光传感器 $43 \sim 46$, 在乙腈中, 仅有 PPi 诱导 其荧光淬灭, 为典型的 PET 过程. 相比其他阴离子, 如 $\mathrm{HSO}_{4}^{-}, \mathrm{CH}_{3} \mathrm{CO}_{2}^{-}, \mathrm{I}^{-}, \mathrm{Br}^{-}, \mathrm{F}^{-}, \mathrm{H}_{2} \mathrm{PO}_{4}^{-}$, 探针 $43 \sim 46$ 均对 PPi 表现出较强的络合作用, 络合常数分别为 $5.43 \times 10^{6}, 1.01 \times 10^{8}, 3.58 \times 10^{6}, 6.76 \times 10^{6} \mathrm{~L}^{6} \mathrm{~mol}^{-1}$. 其 中探针 44 表现出对 PPi 最强的络合能力, 这可能是因为 探针 44 具有双葱荧光团构成的刚性环状结构, 对络合 PPi 起到很好的促进作用.

Sessler 等 ${ }^{[49}$ 报道了基于氢键相互作用, 以荧光素为 荧光团、杯 $[4]$ 吡咯为受体的 PPi 荧光探针 $\mathbf{4 7}$, 该探针在 乙腈-水 $(V: V=96: 4)$ 体系中对 $\mathrm{PPi}$ 具有较好的选择性, 分别是 $\mathrm{F}^{-}$的 10 倍, $\mathrm{Cl}^{-}$的 200 倍, $\mathrm{H}_{2} \mathrm{PO}_{4}^{-}$的 3 倍. 作为

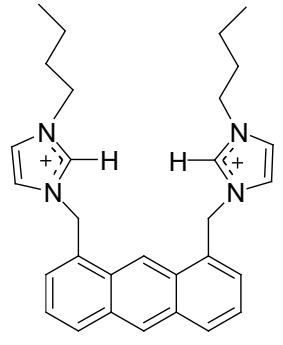

43

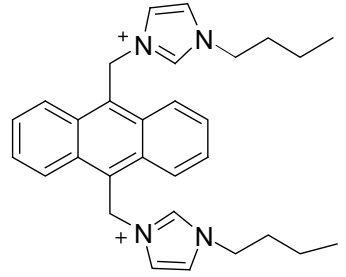

45<smiles></smiles>

44

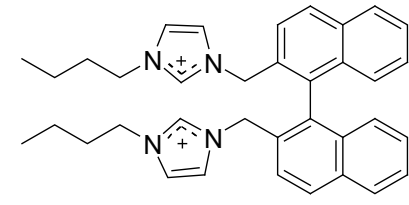

46
对比的探针 48 和 49 对 PPi 的选择性较差, 主要是因为 探针 $\mathbf{4 7}$ 中存在的硫嫝基团提供了更多的氢键位点与 $\mathrm{PPi}$ 的负电中心相结合.
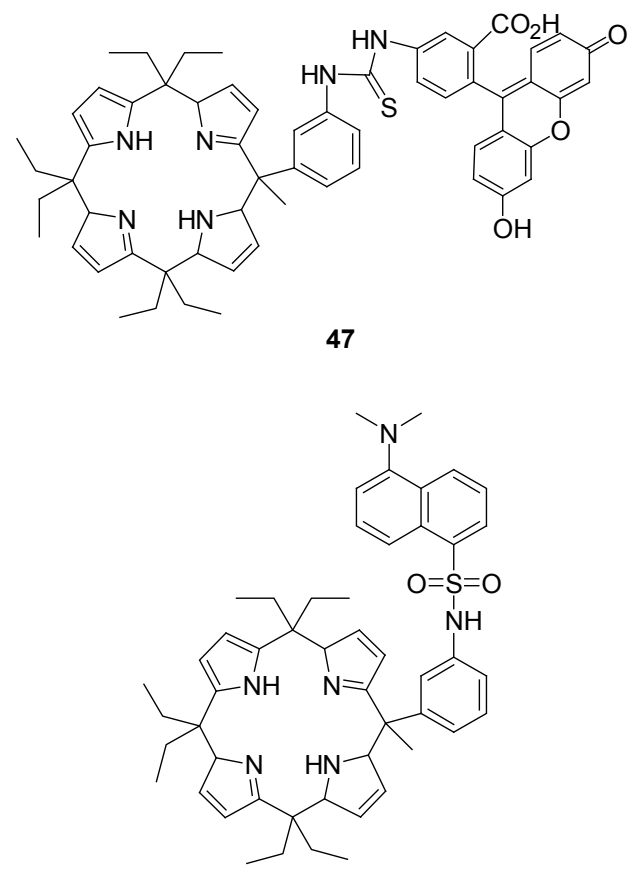

48

值得注意的是近年来单纯基于静电或氢键作用的 PPi 苂光探针已经报道很少. 如前面提到的, 最新的设 计策略是发展 DPA-M ${ }^{2+}$ 络合、静电或氢键协同作用的 PPi 苂光探针 ${ }^{[24,36,37,45]}$.

\section{5 其他类型识别与传感}

Hong 研究组 ${ }^{[50]}$ 近来报道了酚氧桥连的双核锌离子 


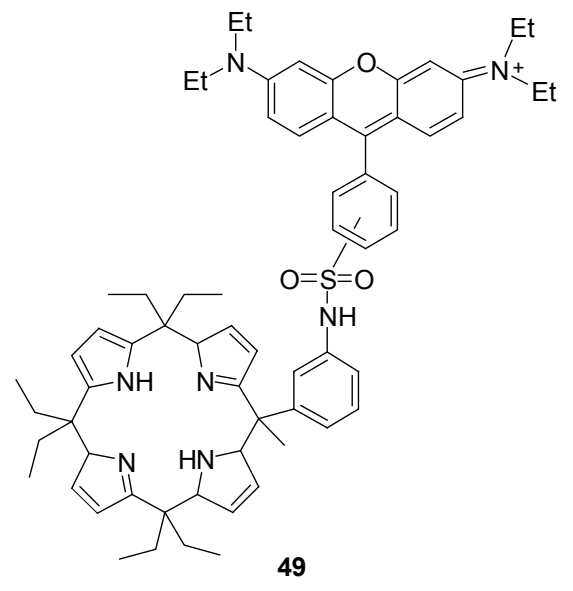

络合物与嗍酸衍生物组成的化学传感体系 $\mathbf{5 0}$, 成功地 将其用于水相或生物体系中 PPi 和三磷酸核苷(NTP)的 选择性识别(Scheme 3). 该高效的选择性识别归因于传 感体系对不同分析物的检测基于不同的络合机制. 在未 加入待分析物前, 硼酸衍生物的存在使得传感体系的苂
光大部分淬灭. PPi 加入后, 由于 $\mathrm{PPi}$ 与双核锌离子络合 物具有更强的结合能力，嗍酸衍生物被置换出来，导致 检测体系的荧光大为增强. 如果检测体系中加入的是 NTP，尽管 NTP 中的三磷酸残基可以与双核锌离子络合 物受体结合，但是与此同时，硼酸衍生物与 NTP 中五碳 糖单元中的邻位羟基成酯而有效结合, 使得传感器体系 50 与 NTP 组成了一个三分子的复合物, 最终导致检测 体系的荧光信号进一步降低. 虽然该传感体系可以有效 区分检测 PPi 和 NTP, 但是该体系组成较为复杂, 这无 疑限制了其在实际生物检测中的应用范围.

近年来，水溶性共轭聚合物作为一类新型荧光传 感器得到广泛关注. 共轭聚合物独特的 “分子导线” 功 能, 实现了荧光信号的放大, 可用于多种生物物种(如 生物大分子、生物小分子、离子等)的检测 ${ }^{[51]}$. Schanze 等 ${ }^{[52]}$ 设计合成了一个连有多胺基团的聚苯乙炔荧光探 针 51, 该探针在 $\mathrm{pH} 6.5$ 的 MES 缓冲溶液中具有较高的

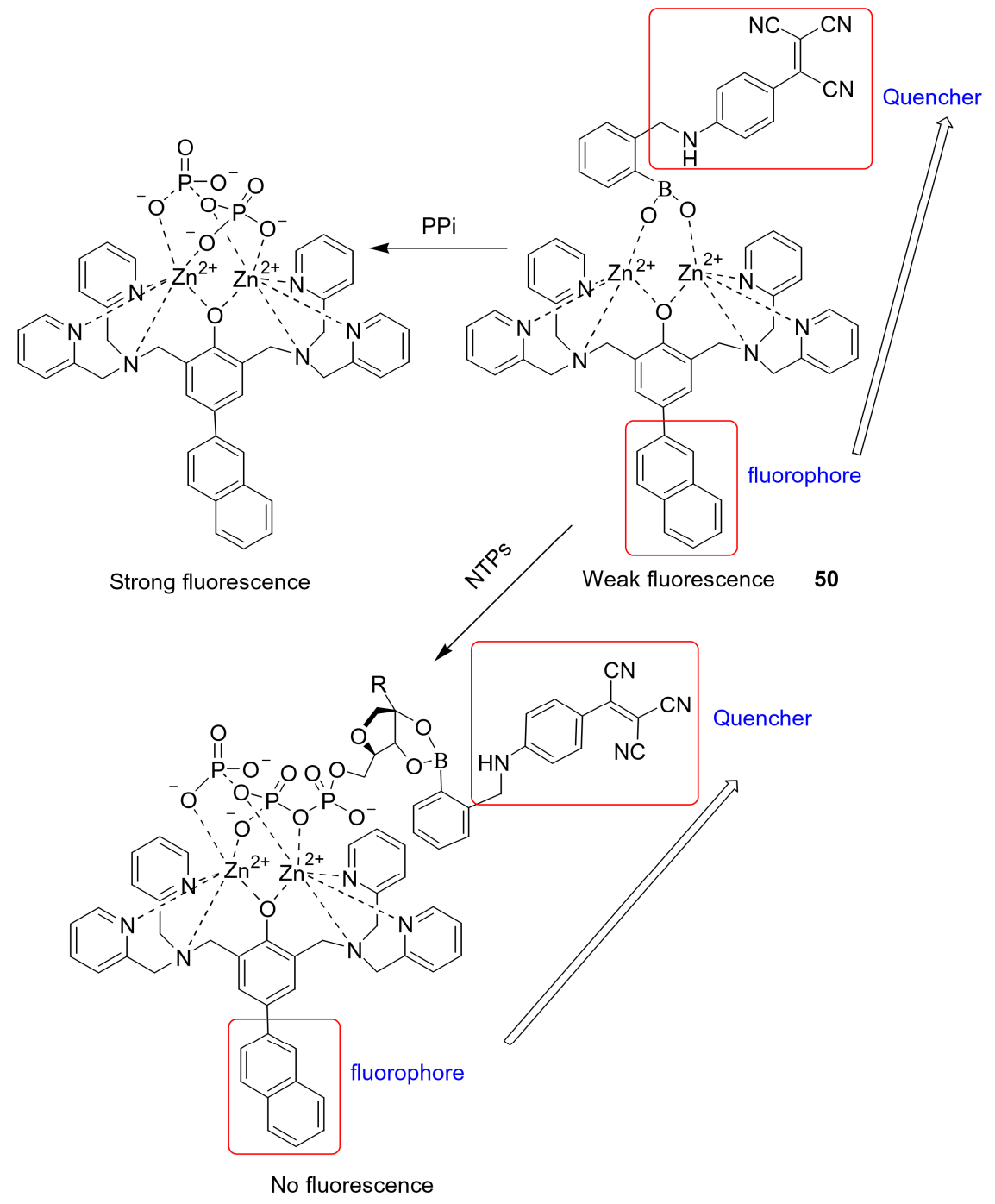

Scheme 3 
量子产率. 随着 PPi 浓度的增加, 吸收光谱 $400 \mathrm{~nm}$ 处的 峰强度逐渐降低, 而 $430 \mathrm{~nm}$ 处出现一个新的吸收峰. 这 表明聚苯乙炔高聚物 51 实现了由 “自由链态” 到 “聚 集链态” 的转换. 与此同时, 聚合物 51 的最大荧光发射 谱带也发生了从 433 到 $520 \mathrm{~nm}$ 的红移, 这主要是因为高 聚物链充分接近时，产生有效的 “分子内激子耦合” 现 象, 导致低能量的 “聚集链态” 出现. $\mathrm{Pi}, \mathrm{HSO}_{4}^{-}$, $\mathrm{CH}_{3} \mathrm{CO}_{2}^{-}, \mathrm{I}^{-}, \mathrm{Br}^{-}, \mathrm{F}^{-}$等无机离子都不能诱导荧光和吸 收光谱的变化. 不足之处是生物体系中重要的阴离子 ATP、ADP 等会对 PPi 的检测造成干扰.

\section{5 结论和展望}

DPA-金属离子络合物, 尤其是 $\mathrm{DPA}-\mathrm{Zn}^{2+}$ 络合物, 作为识别基团对 PPi 有着显著的亲和性和选择性识别能 力. DPA- $\mathrm{Zn}^{2+}$ 络合物与多种苂光团或者荧光指示剂组合 而成的化学传感体系已经被广泛用于 PPi 荧光识别与传 感. 但是目前报道的 PPi 荧光探针仍有许多不足之处. 在水溶性方面, 生物体系都是水环境, 发展具有生物应 用前景的荧光探针首先需要其有着良好的水溶性, 但是 目前纯水体系的荧光探针仍占少数; 在选择性方面, 生 物体系组成复杂, 电荷相同结构相似的含磷生物阴离子 往往同时存在, 从多种磷酸衍生物中专一性地识别 PPi, 迄今为止这类苂光探针依然较少.

因此, 该领域在未来研究中面临的主要挑战仍然是 发展新型荧光识别与传感体系, 包括设计合成新型近红 外荧光探针, 能够专一性地识别 $\mathrm{PPi}$, 避免一些相似含 磷阴离子的干扰. 在提高检测灵敏度方面, 除使用荧光 传感机制中最为常见的 PET, ICT 和激基缔合物机理之 外，联合使用一些其他的荧光识别机理，如苂光共振能 量转移(FRET)、跨键能量转移(TBET) 等近年来发展迅速 的检测策略，将是解决这一问题的有效途径之一.

总的来说, 近年来各种类型的 PPi 苂光传感器发展 迅速. 一些基于 DPA- $\mathrm{Zn}^{2+}$ 识别基团的 PPi 苂光传感器已 经在化学、生物和医学等领域显示出极为重要的研究价 值和应用前景. 我们有理由相信，在不久的将来，通过 化学家和生物学家的共同努力, 新一代高选择性和高灵 敏度的 PPi 苂光探针必将在苂光识别与传感领域广泛应 用.

\section{References}

[1] Heinonen, J. K. Biological Role of Inorganic Pyrophosphate, Kluwer Academic Publishers, Norwell, 2001.

[2] Ronaghi, M.; Karamohamed, S.; Pettersson, B.; Uhlén, M.; Nyrén, P. Anal. Biochem. 1996, 242, 84

[3] Xu, S.; He, M.; Yu, H.; Cai, X.; Tan, X.; Lu, B.; Shu, B. Anal. Biochem. 2001, 299, 188

[4] (a) Kim, S. K.; Lee, D. H.; Hong, J.-I.; Yoon, J. Acc. Chem. Res.
2009, 42, 23 .

(b) Hargrove, A. E.; Nieto, S.; Zhang, T.; Sessler, J. L.; Anslyn, E. V. Chem. Rev., 2011, 111, 6603 .

(c) Ngo, H. T.; Liu, X.; Jolliffe, K. A. Chem. Soc. Rev. 2012, 41, 4928.

[5] Vance, D. H.; Czarnik, A. W. J. Am. Chem. Soc. 1994, 116, 9397.

[6] Lee, D. H.; Im, J. H.; Son, S. U.; Chung, Y. K.; Hong, J.-I. J. Am. Chem. Soc. 2003, 125, 7752.

[7] Jang, Y, J.; Jun, E. J.; Lee, Y. J.; Kim, Y. S.; Kim, J. S.; Yoon, J. J. Org. Chem. 2005, 70, 9603.

[8] Lee, H. N.; Swamy, K. M. K.; Kim, S. K.; Kwon, J.-Y.; Kim, Y.; Kim, S.-J.; Yoon, Y. J.; Yoon, J. Org. Lett. 2007, 9, 243.

[9] Chen, W.-H.; Xing, Y.; Pang, Y. Org. Lett. 2011, 13, 1362.

[10] Kim, M. J.; Swamy, M. K. K.; Lee, K. M.; Jagdale, A. R.; Kim, Y.; Kim, S.-J.; Yoo, K. H.; Yoon, J. Chem. Commun. 2009, 7215.

[11] Das, P.; Bhattacharya, S.; Mishra, S.; Das, A. Chem. Commun. 2011, 47, 8118 .

[12] Kim, H. J.; Lee, J. H.; Hong, J.-I. Tetrahedron Lett. 2011, 52, 4944.

[13] Zhang, J. F.; Kim, S.; Han, J. H.; Lee, S.-J.; Pradhan, T.; Cao, Q. Y.; Lee, S. J.; Kang, C.; Kim, J. S. Org. Lett. 2011, 13, 5294.

[14] Jia, J.; Tang, X.; He, Y. F.; Zhang, M. Y.; Xing, G. W. Chin. J. Org. Chem. 2012, 32, 1803 (in Chinese).

(㚘佳，唐茜，何颖芳，张梦雨，邢国文，有机化学，2012，32， 1803.)

[15] Su, G.; Liu, Z.; Xie, Z.; Qian, F.; He, W.; Guo, Z. Dalton Trans. 2009, 7888 .

[16] Yang, S.; Feng, G.; Williams, N. H. Org. Biomol. Chem. 2012, 10, 5606.

[17] Gu, Z. Y, Xu, Q. C, Xing, G. W. Prog. Chem. 2013, 25, 1302 (in Chinese). (古振远, 徐勤超, 邢国文, 化学进展, 2013, 25, 1302.)

[18] Lee, D. H.; Kim, S. Y.; Hong, J.-I. Angew. Chem., Int. Ed. 2004, $43,4777$.

[19] Roy, B.; Rao, A. S.; Ahn, K. H. Org. Biomol. Chem. 2011, 9, 7774.

[20] Pathberiya, L. G.; Barlow, N.; Nguyen, T.; Graham, B.; Tuck, K. L. Tetrahedron 2012, 68, 9435.

[21] Lee, D.-N.; Jo, A.; Park, S. B.; Hong, J.-I. Tetrahedron Lett. 2012, 53,5528 .

[22] Huang, X.; Guo, Z.; Zhu, W.; Xie, Y.; Tian, H. Chem. Commun. 2008, 5143.

[23] Shao, N.; Wang, H.; Gao, X.; Yang, R.; Chan, W. Anal. Chem. 2010, $82,4628$.

[24] Xu, Q. C; Wang, X. F.; Xing, G. W.; Zhang, Y. RSC Adv. 2013, 3, 15834.

[25] Park, C.; Hong, J.-I. Tetrahedron Lett. 2010, 51, 1960.

[26] Ravikumar, I.; Ghosh, P. Inorg. Chem. 2011, 50, 4229.

[27] Cheng, T.; Wang, T.; Zhu, W.; Chen, X.; Yang, Y.; Xu, Y.; Qian, X. Org. Lett. 2011, 13, 3656.

[28] Cho, H. K.; Lee, D. H.; Hong, J.-I. Chem. Commun. 2005, 1690

[29] Kim, S. Y.; Hong, J.-I. Bull. Korean Chem. Soc. 2010, 31, 716.

[30] Lee, H. N.; Xu, Z.; Kim, S. K.; Swamy, K. M. K.; Kim, Y.; Kim, S.-J.; Yoon, J. J. Am. Chem. Soc. 2007, 129, 3828.

[31] Wen, J.; Geng, Z.; Yin, Y.; Zhang, Z.; Wang, Z. Dalton Trans. 2011, 40, 1984.

[32] Han, M. S.; Kim, D. H. Angew. Chem., Int. Ed. 2002, 41, 3809.

[33] Han, M. S.; Kim, D. H. Bioorg. Med. Chem. Lett. 2003, 13, 1079.

[34] Hanshaw, R. G.; Hilkert, S. M.; Jiang, H.; Smith, B. D. Tetrahedron Lett. 2004, 45, 8721.

[35] Morgan, B. P.; He, S.; Smith, R. C. Inorg. Chem. 2007, 46, 9262.

[36] Lee, J. H.; Park, J.; Lah, M. S.; Chin, J.; Hong, J. Org. Lett. 2007, 9, 3729 .

[37] Huang, F.; Cheng, C.; Feng, G. J. Org. Chem. 2012, 77, 11405. 
[38] Surman, A. J.; Bonnet, C. S.; Lowe, M. P.; Kenny, G. D.; Bell, J. D.; Toth, E.; Vilar, R. Chem. Eur. J. 2011, 17, 223.

[39] Nonaka, A.; Horie, S.; Jamesb, T. D.; Kubo, Y. Org. Biomol. Chem. 2008, 6, 3621.

[40] McDonough, M. J.; Reynolds, A. J.; Lee, W. Y. G.; Jolliffe, K. A. Chem. Commun. 2006, 2971.

[41] Butler, S. J.; Jolliffe, K. A. Org. Biomol. Chem. 2011, 9, 3471.

[42] Carolan, J. V.; Butler, S. J.; Jolliffe, K. A. J. Org. Chem. 2009, 74, 2992.

[43] Lee, D. H.; Kim, S. Y.; Hong, J.-I. Tetrahedron Lett. 2007, 48 4477.

[44] Chen, Z.; Lu, Y.; He, Y.; Huang, X. Sens. Actuators, B: Chem. 2010, 149, 407.

[45] Sokkalingam, P.; Kim, D. S.; Hwang, H.; Sessler, J. L.; Lee, C.-H. Chem. Sci. 2012, 3, 1819.

[46] Kim, S. Y.; Hong, J.-I. Tetrahedron Lett. 2009, 50, 1951.
[47] Nishizawa, S.; Kato, Y.; Teramae, N. J. Am. Chem. Soc. 1999, 121, 9463.

[48] Kim, S. K.; Singh, N. J.; Kwon, J.; Hwang, I.-C.; Park, S. J.; Kim, K. S.; Yoon, J. Tetrahedron 2006, 62, 6065.

[49] Anzenbacher, P. Jr; Jursíková, K.; Sessler, J. L. J. Am. Chem. Soc. 2000, 122, 9350.

[50] Lee, J. H.; Jeong, A. R.; Jung, J.-H.; Park, C.-M.; Hong, J.-I. J. Org. Chem. 2011, 76, 417.

[51] (a) Zhu, C.; Liu, L.; Yang, Q.; Lv, F.; Wang, S. Chem. Rev. 2012, 1124687.

(b) Wang, Y.-J.; Gu, Z.-Y., Xing, G. W. Chem. Asian J. 2012, 7, 489.

(c) Wang, Y.-J.; Xin, B.-J.; Duan, X.-R.; Xing, G.-W.; Wang, S. Macromol. Rapid Commun. 2010, 31, 1473.

[52] Zhao, X.; Schanze, K. S. Chem. Commun. 2010, 46, 6075. 